\title{
Additives and modifiers for cyanate ester resins
}

Jean-Pierre Pascault, Jocelyne Galy and Françoise Méchin

Laboratoire des Matériaux Macromoléculaires, INSA de Lyon, URA CNRS 507,

20 avenue Albert Einstein, 69621 Villeurbanne Cedex, France

In Chemistry \& Technology of Cyanate Ester Resins, Ed. I. Hamerton, Blackie Academic \& Professional, Glasgow, 1994, Chapter 5, pp. 112-150. 


\title{
Additives and modifiers for cyanate ester resins
}

\author{
J.P. PASCAULT, J. GALY and F. MECHIN
}

\section{Introduction}

Other chapters in this book are concerned with the mechanism of cure of cyanate esters (CE), kinetics, processing and the structure-properties relationships. However, all these results mainly concern pure cyanates. The major uses of these polymers are in the electronics industry (printed circuit boards) and in the aerospace industry with a market of 70 and 30\%, respectively [1]. Many of these applications required formulated cyanates for the following reasons:

- Processing. Cyanate esters can be fabricated by all known composite-forming processes, therefore the viscosity, tack and pot life of the reactive system need to be adapted to the process.

- Curing cycle. Cyanate esters networks have high glass transition temperatures $\left(T_{\mathrm{g}}\right)$, therefore the system must be cured at high temperatures; in order to achieve complete conversion, bisphenol Abased dicyanate (DCBA) and its analogous networks require curing temperatures greater than $250^{\circ} \mathrm{C}$. This is viewed as a disadvantage in terms of manufacturing time and expense. Different comonomers and catalysts could be used to reduce these drawbacks. The aim is to apply epoxy-like processibility (RTM, filament winding, prepregs, molding), i.e. without the processing difficulties associated with a high performance resin system.

- Properties. It is well known that high temperature thermosets are brittle and lack the toughness of thermoplastics. Engineering thermoplastics and/or reactive rubbers could be blended with cyanate esters to enhance toughness without depressing $T_{\mathrm{g}}$ too much (and this strategy is often employed in epoxy formulations).

- Costs. Most cyanate esters are in the $f 30-40 / \mathrm{kg}(\$ 20-45 / \mathrm{lb})$ range, compared to high performance epoxies at $£ 15-45 / \mathrm{kg}(\$ 10-30 / \mathrm{lb})$ and BMls at $\mathrm{f60}-90 / \mathrm{kg}(\$ 40-60 / \mathrm{lb})$. For applications at moderate temperature, blends of epoxy and cyanate are especially interesting. In order to reduce the cost, fillers are often added to the formulations; however, to our knowledge no cyanate ester formulations are manufactured with fillers (silica, calcium carbonate, mica, aluminum powder, etc.).

Cyanates can be modified with a wide variety of reactive compounds and our objective is not to give an exhaustive list of these compounds but rather to report data on simplified systems that can be considered as models of commercially available formulations. As mentioned above and depending on the application, these formulations may be based on some of the following components:

- cyanate monomer and its prepolymer

- epoxy prepolymers: bisphenol A diglycidyl ether (BADGE), $N, N, N^{\prime}, N^{\prime}$-tetraglycidyl diamino-4,4' diphenylmethane (TGDDM), N,N,O-triglycidyl amino-4-phenol (TGAP)

- bismaleimides (BMI) (BT resins)

- catalyst

- thermoplastics

- core-shell rubbers

- reactive rubbers 
- reactive diluents

- fibers: glass, carbon, aramid, etc.

An overview of cyanate ester resin systems is given in the Appendix. This chapter reports the influence of active hydrogen compounds, epoxy, bismaleimides, thermoplastics and reactive rubbers used with cyanate ester, and how these compounds modify the rate of reactions, the kinetics, the gelation and the properties of the resulting networks.

\section{Chemistry with active hydrogen additives}

Cyanate ester monomers are seldom used alone. Most of the time, they are cured in the presence of catalysts or various kinds of oligomer that are meant to modify the final properties of the network and usually bear reactive functions such as alcohols or phenols, amines and often epoxies. Moreover, even in the absence of any modifier, one has to cope with water, which is almost always present and affects the kinetics as well as the material properties. It is, therefore, necessary to investigate precisely the polycyclotrimerization chemistry in the presence of these reactive functions.

\subsection{Effect of the cure atmosphere: autocatalytic behavior}

For the polycyclotrimerization of monomers bearing two reactive functions, one can expect from the mean field theory a conversion at gelation equal to 0.50 [2-4]. Several hypotheses have to be made to support these calculations:

- cyclotrimerization is the only reaction involved

- there is no cyclization reaction (intramolecular reaction)

- there is no substitution effect (any cyanate function, whether it belongs to a non-reacted monomer or to any higher cluster has the same reactivity)

- the reaction is chemically and not diffusion-controlled.

However, two types of experimental value can be found when considering the literature. The theoretical value of 0.50 is claimed by Bauer's group [5] (see chapter 3 ), whereas several other workers report a much higher conversion at the gel $\left(x_{\text {gel }}>0.60\right)$. This discrepancy was discussed by Williams [4] and Gupta $[6,7]$ in terms of statistics, but they did not consider a possible influence of the reaction conditions and especially of the cure atmosphere. In fact, most authors proceed under air or do not specify their curing conditions and it is therefore difficult to draw any conclusion.

In our laboratory, to try to understand the underlying phenomena, numerous isothermal cures were followed kinetically with the help of size exclusion chromatography (SEC) and differential scanning calorimetry (DSC). Parallel experiments were run using exactly the same conditions (10 $\mathrm{mg}$ samples in aluminum DSC pans), except for the atmosphere: for each temperature, one batch of samples was cured in air in a bench oven while the other one was cured under argon directly in the DSC oven. Figure 1 displays the results obtained at $200^{\circ} \mathrm{C}$ for bisphenol A dicyanate (DCBA), from which two main features can be deduced:

(i) the reaction proceeds much faster in air

(ii) the gel conversions obtained in both atmospheres are very different, i.e. $x_{\text {gel }}=0.62$ in air whereas $x_{\mathrm{gel}}=0.50$ under argon. This phenomenon was observed for numerous experiments. 
Furthermore, the marked S-shape displayed by the $x$ versus time curve obtained in air is no longer observed under argon when the curve is linear at the start. This indicates that the already wellestablished [8] autocatalytic behavior of dicyanate polycyclotrimerization tends to disappear in an inert atmosphere.

Several reasons can be suggested from the literature to account for the difference between $x_{\text {gel }}($ air) and $x_{\text {gel }}$ (argon).

- Monofunctional species could create linear junctions and dead chain ends. However, 24 mole\% monofunctional monomer would be necessary to increase $x_{\text {gel }}$ from 0.50 to 0.62 . Such an amount is very unlikely, and in addition would necessarily induce the same increase under argon.

- Linear species such as the four-membered ring cyanate dimer or some kind of adduct between a cyanate and a compound bearing a labile hydrogen atom (iminocarbonate, isourea) could be formed. The former has never been clearly identified, and its stability seems doubtful. More probably, the air moisture would trigger a change in the reaction mechanism.

- One of the assumptions of the mean field theory could be wrong in this case: cyclization reactions could interfere [5], the reaction could become diffusion-controlled very early [6, 7] or a substitution effect could lessen the reactivity of the second cyanate function of an already reacted monomer $[4,5]$.

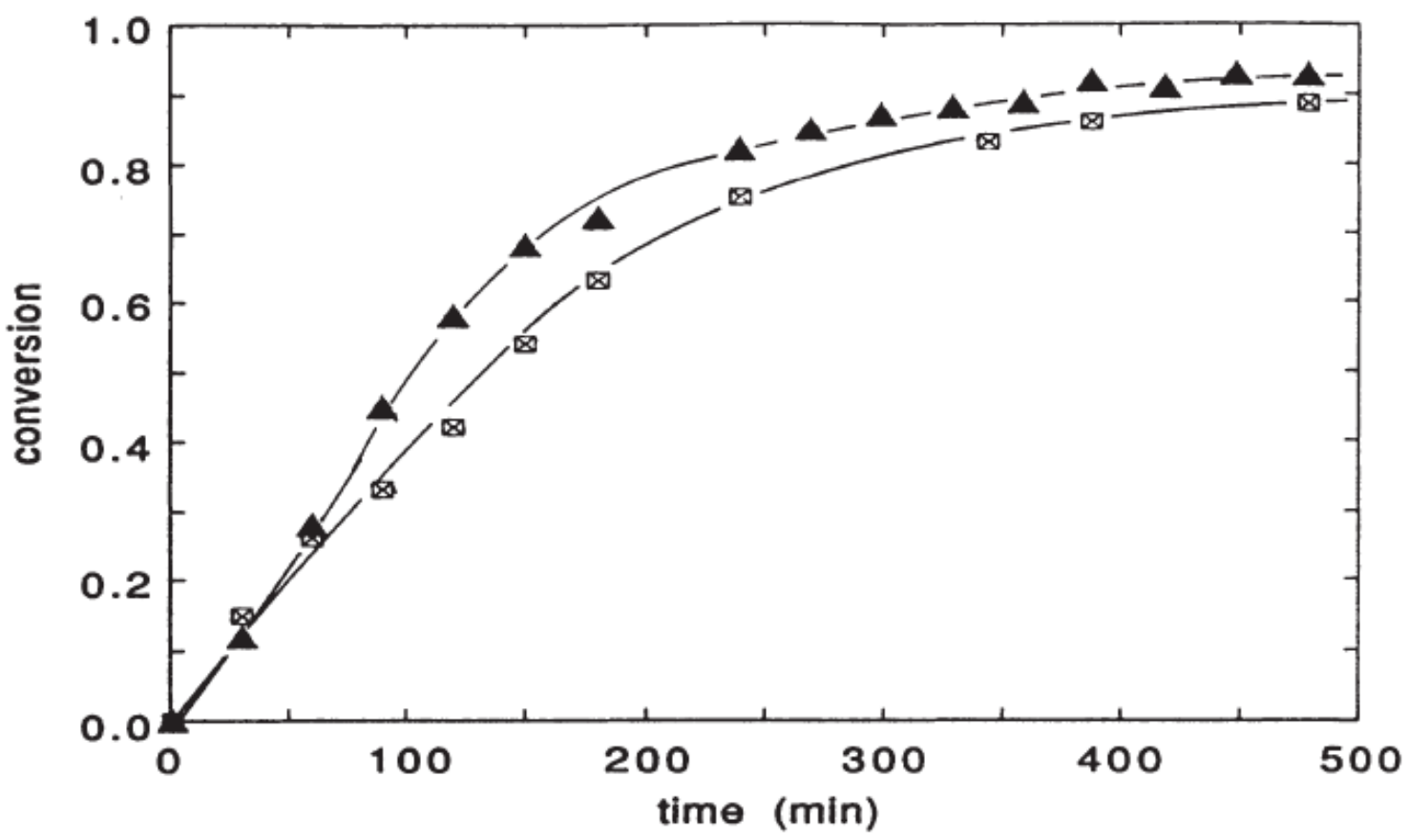

Figure 1. Evolution of the cyanate conversion $x$ (measured by DSC) of DCBA as a function of time during an isothermal cure performed at $200^{\circ} \mathrm{C}$. $\boldsymbol{\Delta}$, cure in air; $囚$, cure under argon.

In any case one has to bear in mind that the cure atmosphere (and most probably the air moisture) plays its part. Thus, both the moisture and the small amount of impurities $(<0.5 \%$ in the case of DCBA) induce either a substitution effect which does not exist under argon or the formation of some kind of linear junction. They would also somehow enhance the autocatalytic behavior, as can be seen in Figure 2. 
The parameter $T_{\max }$ is deduced from a first DSC scan performed on a partially-cured sample; it is the temperature associated with the polymerization peak maximum. In air, $T_{\max }$ decreases by $50^{\circ} \mathrm{C}$ as $x$ increases; on the contrary, it drops from only 320 to $305^{\circ} \mathrm{C}$ under argon. The thermally-induced polycyclotrimerization starts at a lower temperature for a partially-cured oligomer (such as commercial prepolymers derived from DCBA, AroCy ${ }^{\circledR}$ B-30 or B-50, for example) and must consequently be catalyzed by a reactive intermediate, which should be formed in greater amounts in air than under argon.

It is well known from Bauer's work [8] that the iminocarbonate resulting from the condensation of a cyanate with its parent phenol can catalyze the trimerization by forming an adduct with two cyanate functions, thus giving rise to the triazine ring and regenerating the phenol. The iminocarbonate itself is even likely to trimerize [9]. If the air moisture favors its formation, the iminocarbonate can be responsible for the autocatalytic behavior but one can also think of other species. The triazine ring itself, although often quoted as a possible catalyst [8c], is probably not the best candidate since it is formed both in air and in an inert atmosphere; several experiments were run in our laboratory which tend to prove that pure triazine does not promote cyanate cyclotrimerization [10], although some byproducts of its synthesis might [9]. It is not our purpose to discuss these results here, but we will focus on the influence of water on the mechanism. This aspect has also a great importance from a practical point of view, especially for the manufacture of prepregs based on glass fibers.

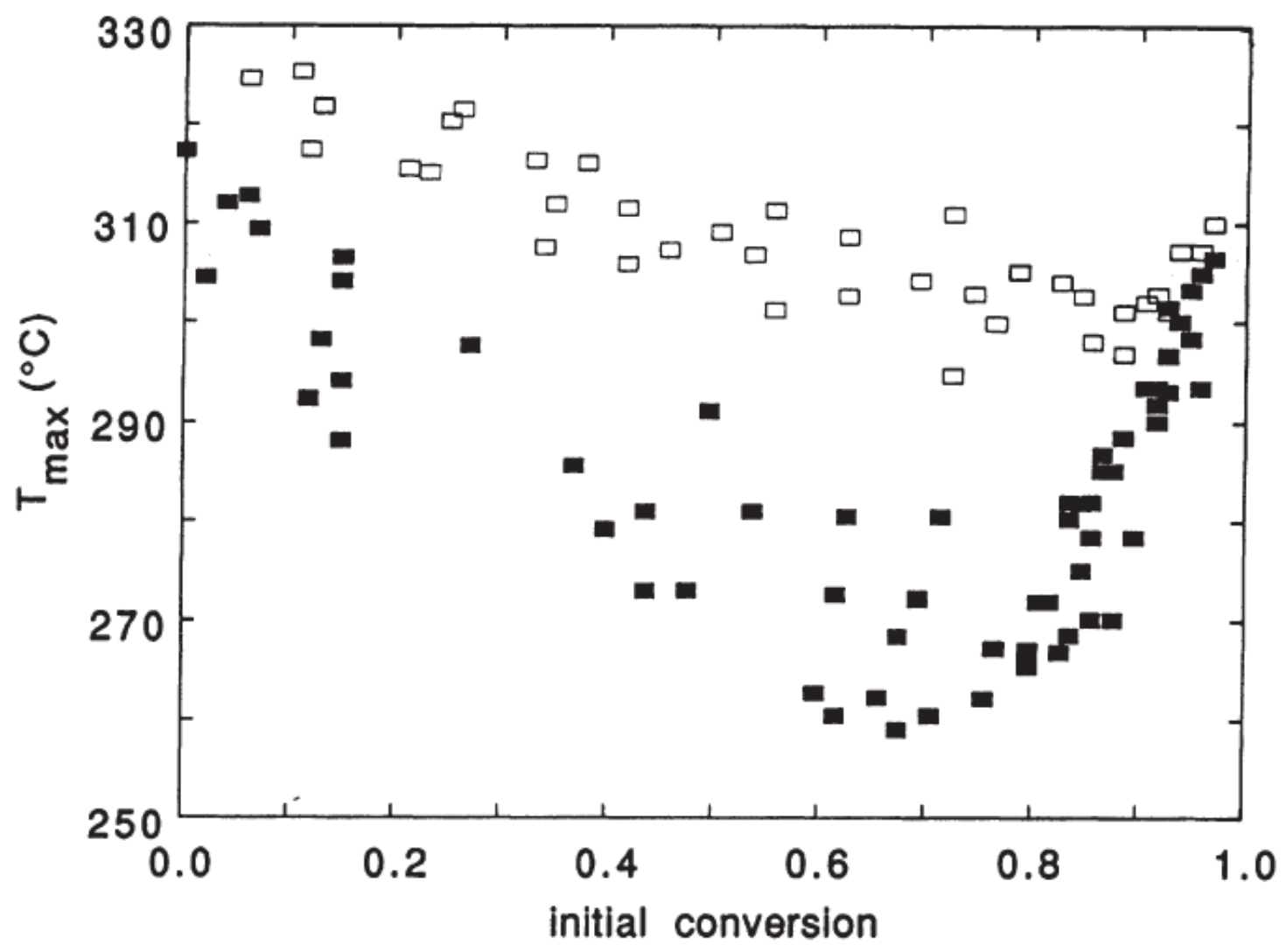

Figure 2. Polymerization exotherm maximum $\left(T_{\max }\right)$ versus conversion $\left(x_{\mathrm{DSC}}\right)$ for the isothermal cure of neat DCBA $\left(T_{i}=150,165,200,225\right.$ and $250^{\circ} \mathrm{C}$ in air ( $\left.\boldsymbol{\square}\right)$ or under argon ( $\square$ ). 


\subsection{Effect of water}

The strong influence of the cure atmosphere suggests that the air moisture might interfere in the mechanism. The hydrolysis of a cyanate function leads to a carbamate (Scheme 1). Above $190^{\circ} \mathrm{C}$, the carbamate function can decompose, giving rise to an amine and evolving $\mathrm{CO}_{2}$ (Scheme 2) (hence the presence of possibly troublesome gaseous bubbles, resulting in voids in composite samples). Finally, the resulting amine can react with another cyanate group, leading to a linear junction.

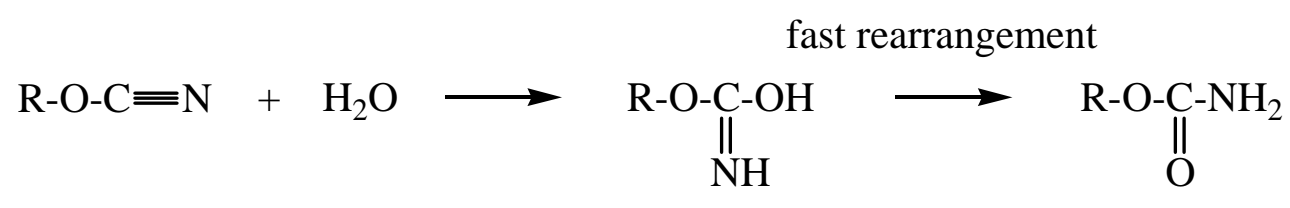

Scheme 1

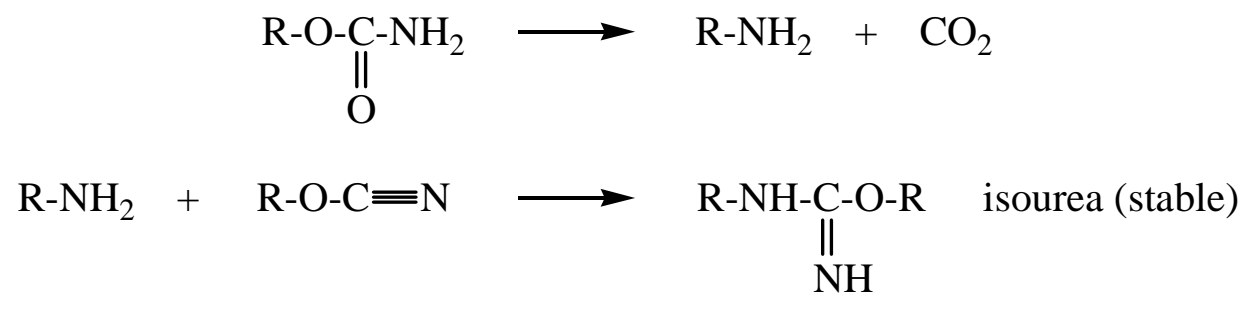

Scheme 2

According to the literature [11,12], one needs a catalyst (often acidic or organometallic, especially Lewis acids such as zinc) to form the carbamate. However, some traces remaining from the cyanate synthesis might be sufficient to induce the formation of minor amounts of carbamate. In order to investigate its possible effects on the reaction kinetics, we prepared large amounts of the pure dicarbamate associated with DCBA, following a procedure (Scheme 3) previously described by Shimp [12].

The resulting compound is a crystalline solid $\left(T_{\mathrm{m}}=200^{\circ} \mathrm{C}\right)$, soluble in molten DCBA. Its structure and purity were fully characterized by FTIR and ${ }^{1} \mathrm{H}$ and ${ }^{13} \mathrm{C}$ NMR. Various amounts of this potential catalyst were then added to the neat monomer to assess its influence on the polycyclotrimerization kinetics.

General aspects. A preliminary DSC study of mixtures of DCBA with its corresponding dicarbamate showed that the latter lowers $T_{\max }$ markedly, without modifying the polymerization heat $\Delta H_{0}$ (relative to the weight of dicyanate monomer only). Small amounts are sufficient to induce a sharp decrease in $T_{\max }$, but do not involve any important weight loss, as can be seen in Table 1 . The carbamate, thus, behaves like a real catalyst. Its effect is comparable to that of an iminocarbonate [9], although the carbamate seems to be more efficient (lower amounts are sufficient to induce the same decrease in $\left.T_{\max }\right)$.<smiles>CC(C)(c1ccc(OC(N)=O)cc1)c1ccc(OC(N)=O)cc1</smiles>

Scheme 3 
Table 1. Thermodynamic features determined from the DSC investigation of the polycyclotrimerization of DCBA in the presence of various amounts of carbamate

\begin{tabular}{|c|c|c|c|c|}
\hline $\begin{array}{c}\text { Carbamate } \\
\text { (\% by weight) }\end{array}$ & $\Delta H_{0} / \mathrm{g}(\mathrm{J} / \mathrm{g})$ & $\Delta H^{\prime}{ }_{0}(\mathrm{~J} / \mathrm{g})$ & $T_{\max }\left({ }^{\circ} \mathrm{C}\right)$ & Weight loss (\%) \\
\hline 0 & 720 & 720 & 317 & - \\
0.5 & 722 & 726 & 306 & - \\
4 & 710 & 740 & 273 & 2 \\
10 & 674 & 750 & 266 & 22 \\
25 & 561 & 750 & 242 & 20 \\
33 & 486 & 730 & 240 & 40 \\
50 & 370 & 740 & 234 & \\
\hline
\end{tabular}

$\Delta H_{0}$, total polymerization heat; $\Delta H^{\prime} 0 / \mathrm{g}$, polymerization heat per gram of dicyanate monomer; $T_{\max }$, reaction enthalpy peak maximum determined on a non-precured reactive mixture.

When large amounts of carbamate are used, one notices that the weight loss becomes very important. In fact, it is greater than the theoretical weight of $\mathrm{CO}_{2}$ which can be evolved (i.e. $28 \%$ of the initial carbamate amount). We did not try to look more closely into this particular feature, although it could suggest possible monomer vaporization. For the following kinetic studies, only small amounts of carbamate were used to avoid these problems.

Effect on the polymerization kinetics. The isothermal cure of DCBA was investigated at 200G C, in air and under argon, in the presence of 0.5 to $4 \%$ by weight (bw), i.e. 0.4 to $3.5 \mathrm{~mole} \%$, carbamate. Figure 3 depicts the increase in conversion $x$ (as evaluated by DSC) observed with $4 \%$ bw additive as the reaction proceeds; the results are compared to those obtained with pure DCBA. It appears that $4 \%$ bw dicarbamate considerably promotes polycyclotrimerization and, moreover, erases the difference between the cure atmospheres. However, it is also worth noting that under argon, adding $0.4 \mathrm{~mole} \%$ carbamate is sufficient to raise the curve to well above that associated with pure monomer in air. Very little carbamate is thus necessary to get the same reaction acceleration as the one induced by air, and this small amount might well originate from the air moisture.

Effect on $T_{\mathrm{g}}$. In previous studies [13], we have shown that for DCBA, the conversion $(x)$ and $T_{\mathrm{g}}$ were linked by a unique one-to-one relationship. This behavior could be perfectly described by using DiBenedetto's equation, as restated by Pascault and Williams [14].

$$
T_{g}=T_{g 0}+\frac{\left(T_{g \infty}-T_{g 0}\right) \lambda x}{1-(1-\lambda) x}
$$

This relation depends neither on the isothermal cure temperature $\left(T_{i}\right)$ nor on the atmosphere. 


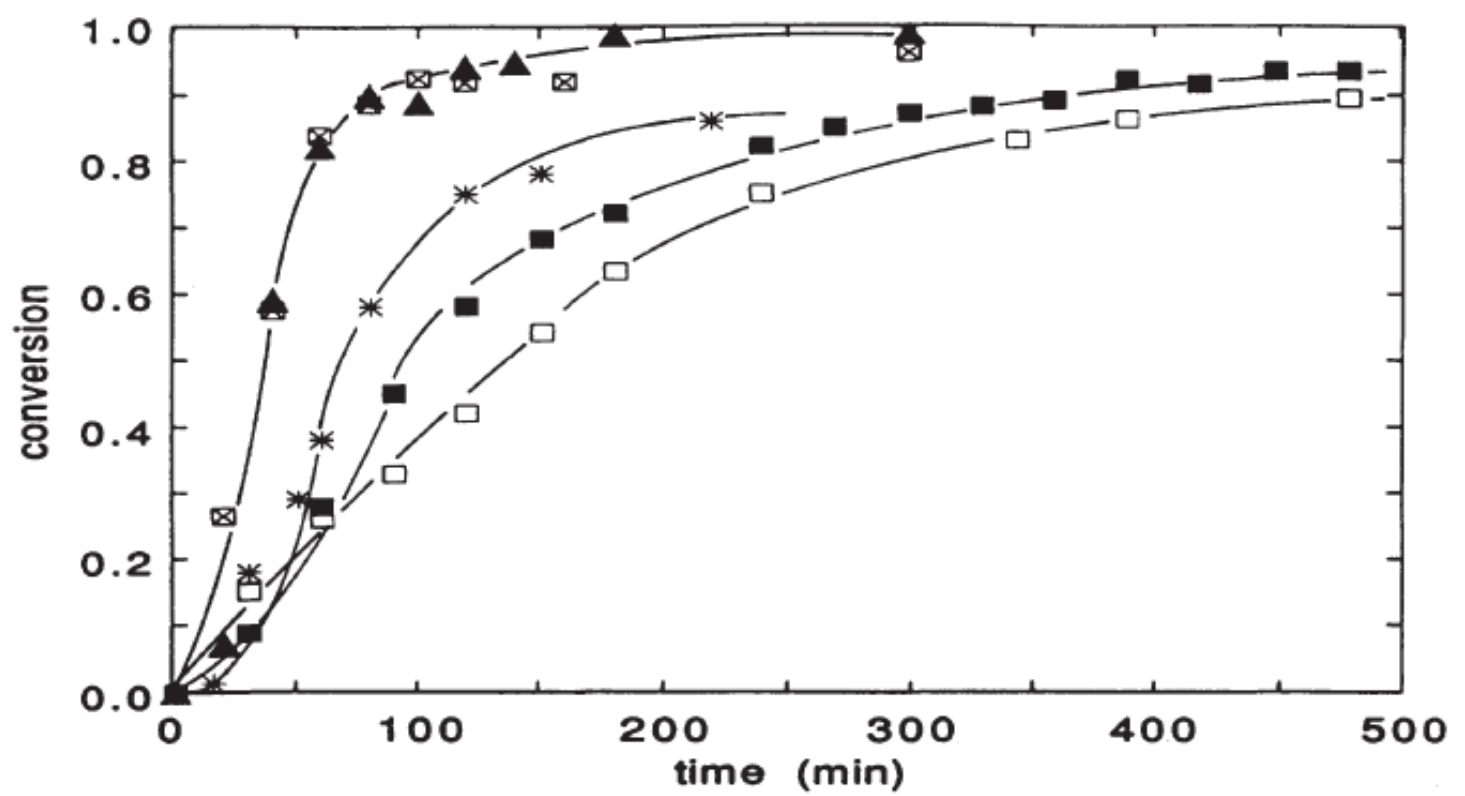

Figure 3. Evolution of the cyanate function conversion $x_{D S c}$ during the isothermal cure of DCBA $\left(T_{\mathrm{i}}=200^{\circ} \mathrm{C}\right)$. $\square$, pure DCBA under argon; $\boldsymbol{\square}$, pure DCBA in air; $*$, DCBA $+0.5 \%$ bw carbamate under argon; $\boldsymbol{\Delta}, \mathrm{DCBA}+4 \%$ bw carbamate under argon; $囚, \mathrm{DCBA}+4 \%$ bw carbamate in air.

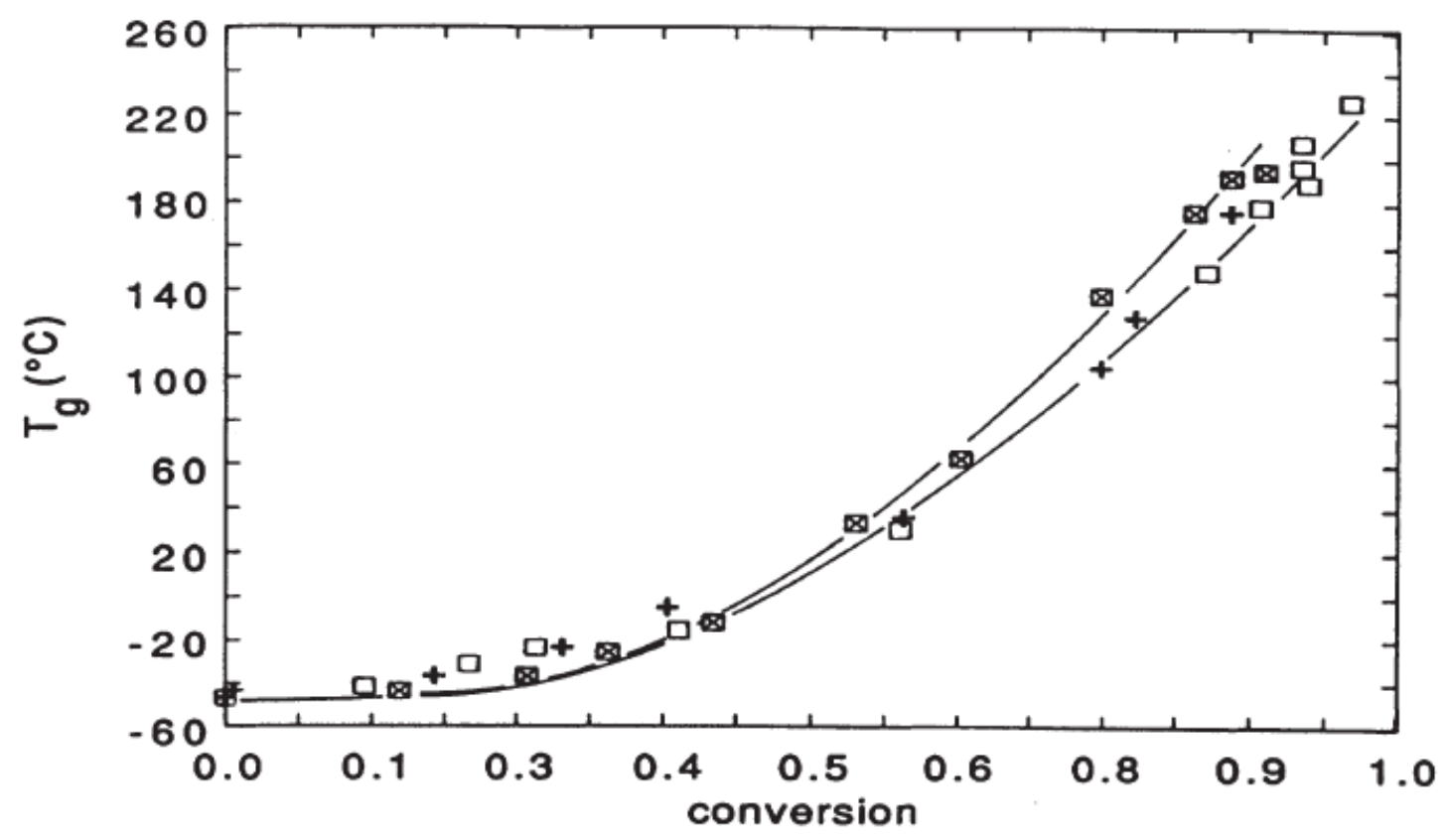

Figure 4. Relationship between $T_{\mathrm{g}}$ and $x_{\mathrm{DSC}}$ for the cure of DCBA $\left(T_{\mathrm{i}}=200^{\circ} \mathrm{C}\right.$, under argon) using various weight amounts of carbamate; $\otimes 0 \%$; $0.5 \%$; $\square, 4 \%$.

In the presence of carbamate, $T_{\mathrm{g}}$ of the partially-cured samples were once again plotted versus conversion. The results obtained for the isothermal cure of DCBA $\left(T_{\mathrm{i}}=200^{\circ} \mathrm{C}\right.$, under argon) using increasing amounts of carbamate are shown in Figure 4. Up to $x \approx 0.6$, all data fall on the same line. However, beyond this value, the various curves diverge: for a given conversion, increasing amounts of carbamate lead to decreasing values of $T_{\mathrm{g}}$. This is consistent with the differences which appear at high 
conversion in Figure 3: for pure DCBA, and whatever the atmosphere, the conversion is limited to about 0.90 because of vitrification (once the $T_{\mathrm{g}}$ has reached $T_{i}$ the reaction becomes diffusion controlled and slows down dramatically). On the contrary, $x$ easily reaches 0.95 in the presence of carbamate: vitrification is delayed and the conversion at which $T_{\mathrm{g}}=T_{\mathrm{i}}$ is higher.

These observations suggest that the structure of the final network is modified by the addition of small amounts of carbamate and would be consistent with the formation of linear species which would decrease the crosslink density. The same phenomenon is supported by referring to the ultimate $T_{\mathrm{g}}$ of the resulting networks, as depicted in Figure 5.

The final $T_{\mathrm{g}}$ collapses as the initial amount of carbamate increases, probably because linear junctions are formed through the action of carbamate, with a concentration roughly proportional to its initial amount.

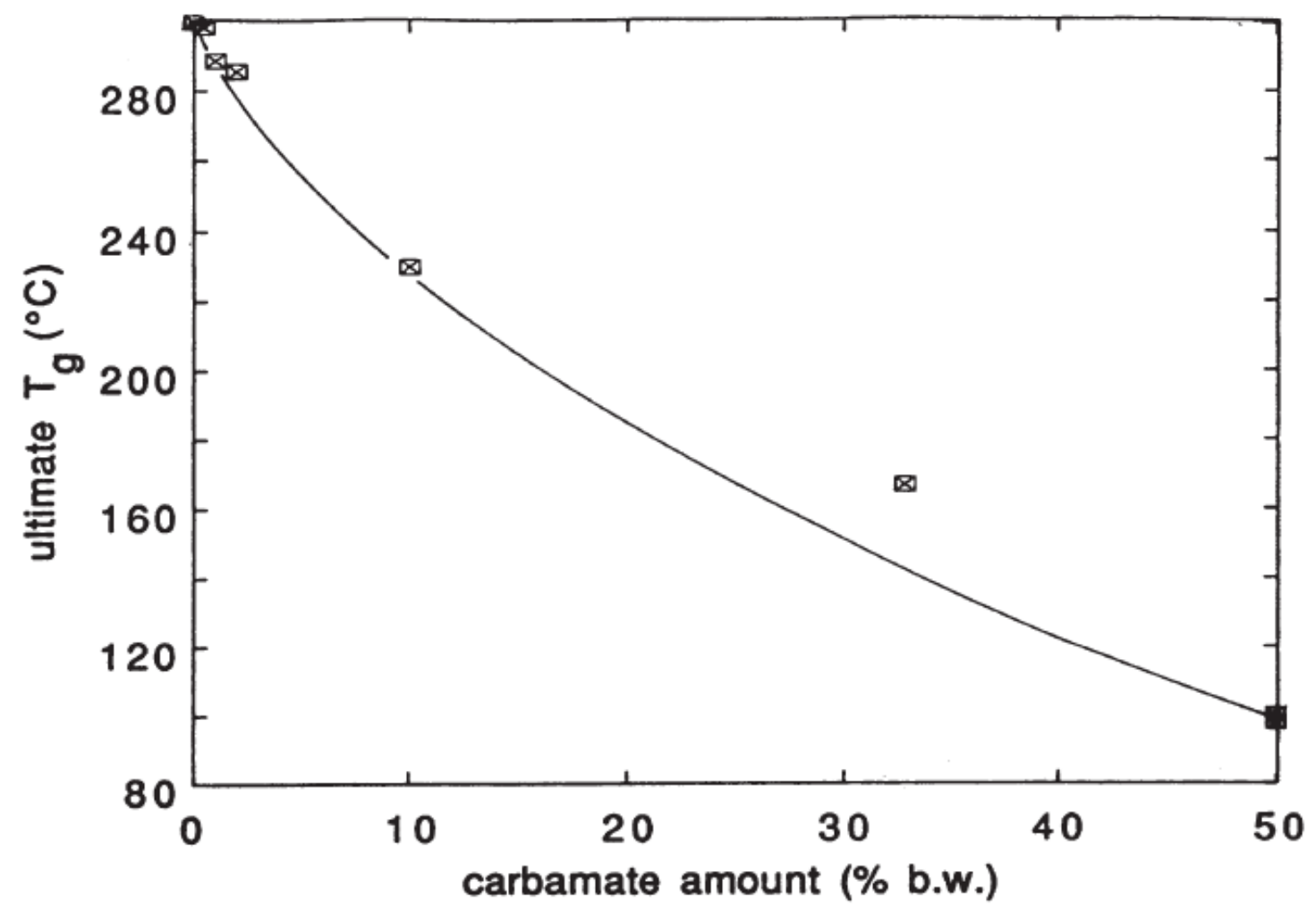

Figure 5. Ultimate $T_{\mathrm{g}}\left(T_{\mathrm{g}} \infty\right)$ of the various fully-cured networks as a function of the initial amount of carbamate ( $T_{\mathrm{g}} \infty$ is obtained from two successive DSC scans performed on uncured systems).

Effect on gelation. The hypotheses and results discussed above can be confirmed by considering the gelation phenomenon. We determined the gel times and conversions associated with the previous isothermal cures by the appearance of an insoluble fraction in tetrahydrofuran. In Figure 6, the resulting conversions $x_{\text {gej }}$ were plotted versus the amount of added carbamate. It is clear that $x_{\text {gej }}$ increases with the amount of added carbamate, whatever the conditions. This supports the formation of increasing amounts of linear junctions as the initial amount of carbamate is increased, as well as our previous conclusions from $T_{\mathrm{g}}$ and from the occurrence of vitrification. Moreover, it seems that the slope of the curve in Figure 6 is slightly smaller in air, which would mean that the air moisture reduces the effect of the carbamate. This once again is consistent with their being involved in the same manner in the mechanism, and the further addition of carbamate would have less influence on $x_{\mathrm{gel}}$. 


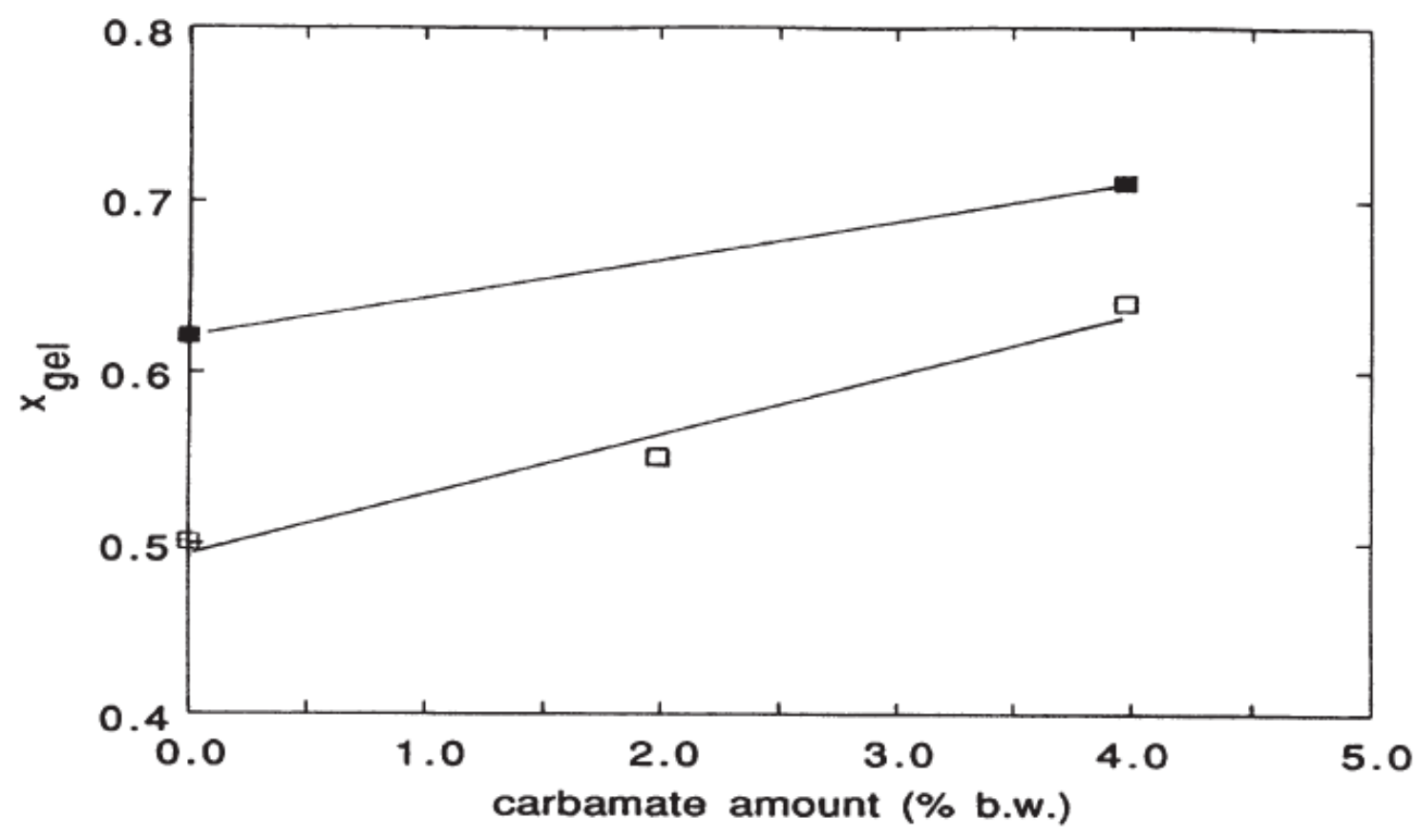

Figure 6. Effect of the initial amount of carbamate on the gel conversions observed for DCBA ( $T_{\mathrm{i}}=200^{\circ} \mathrm{C}$, in air or under argon). $\square$, under argon; $\mathbf{\square}$, in air.

\section{Effect of phenols}

Cyanate esters result from the condensation of phenols or diphenols with cyanogen halides (chapter 2). The parent diphenol and the monosubstituted compound are very difficult to eliminate and, therefore, are often left as impurities in the commercial monomers. Their nature and concentration have a great influence on the cure kinetics, since it is usually accepted that without these impurities, cyanate cyclotrimerization would not occur [8c,15]. Furthermore, alkylphenols (and especially nonylphenol) are widely used as diluents for the organometallic salts which commonly promote the polycyclotrimerization reactions. Therefore, it is important to understand how these compounds can be incorporated into the network. The polymerization of mono- and dicyanates in the presence of wellcontrolled amounts of phenols has consequently been thoroughly investigated $[8 c, 9,16]$.

According to Bauer [8c,15], cyclotrimerization proceeds via the reaction of two cyanate functions with the iminocarbonate resulting from the addition of a third cyanate with a phenol $\mathrm{ArOH}$ (Scheme 4). This phenol is usually left as an impurity from the cyanate synthesis; referring to the mechanism above, it would be the real catalyst of the reaction. Kinetic studies were carried out by directly using mixtures of cyanates and phenols in various proportions.

Model reactions [9]. In order to model this type of reaction, phenol and phenylcyanate were at first mixed in stoichiometric proportions. The reactive system was then cured isothermally $\left(T_{i}=70^{\circ} \mathrm{C}\right)$ in the absence or presence of 2 mole\% additional catalyst. This could be an amine (triethylamine or aniline) or a cyanate derivative (triazine or iminocarbonate). Somewhat surprisingly, the system is not very reactive in the absence of any catalyst. More than $100 \mathrm{~h}$ are necessary to get a complete conversion of the cyanate functions into cyanurate rings; in addition, the triazine turns out to be totally inefficient as a catalyst. 


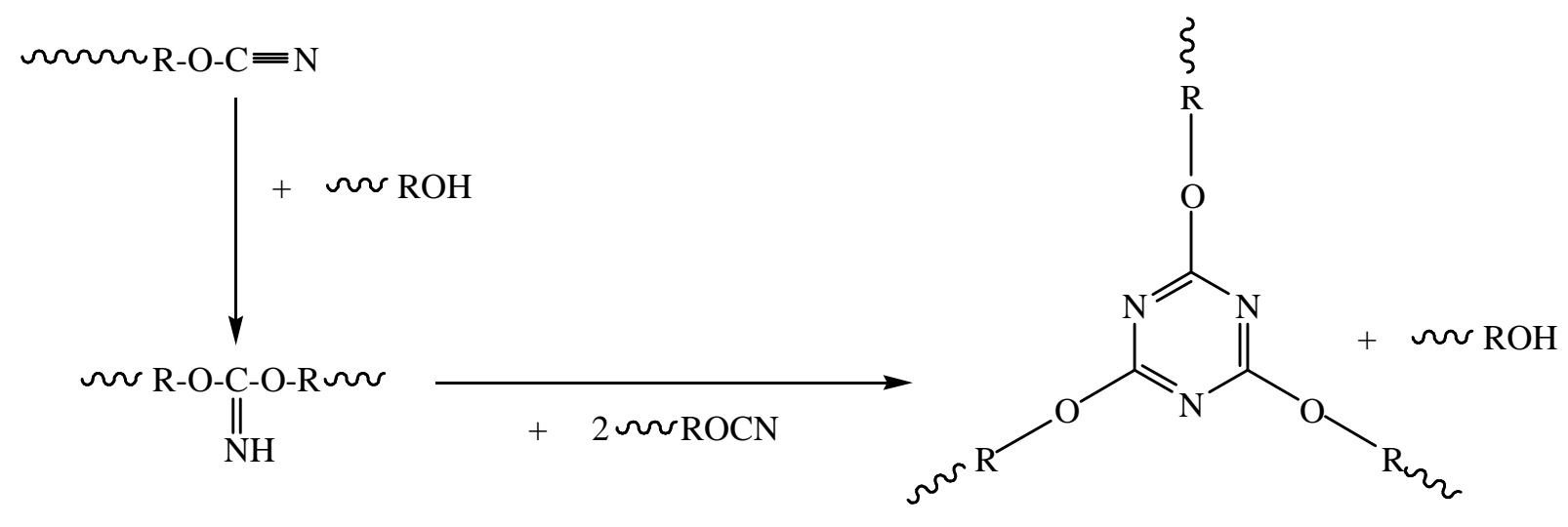

Scheme 4

Only when the adduct of phenylcyanate and phenol (i.e. diphenyliminocarbonate) has been preformed and added in small quantities does one observe an appreciable enhancement of the reaction rate; however, the iminocarbonate soon breaks up (within a few hours) to regenerate its parent phenol and cyanate. Its formation would thus be the limiting step in the mechanism, while its reaction with two additional cyanate functions would proceed much more quickly.

Finally, the use of 2 mole\% amine promotes the cyclotrimerization tremendously. The reaction is actually instantaneous (it takes less than a minute) in the presence of 2 mole\% aniline, which is probably involved in the mechanism via the formation of an isourea (Scheme 5).

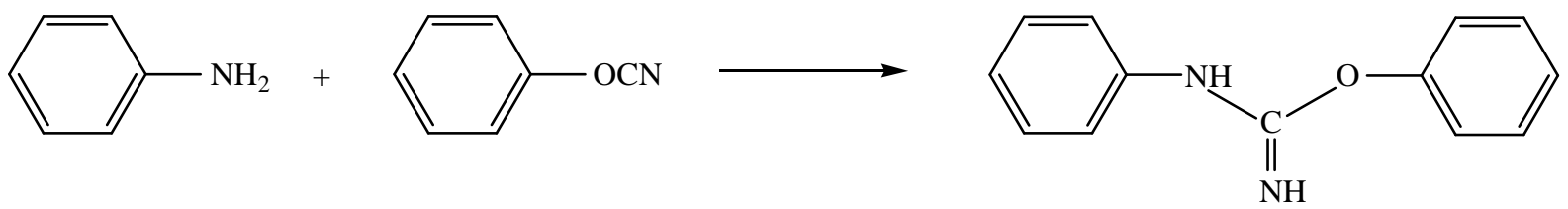

Scheme 5

Even triethylamine, although it does not bear any labile proton, leads to the rapid formation of considerable amounts of iminocarbonate, soon followed by the complete cyclotrimerization of all cyanate functions. This is important to keep in mind as triethylamine often remains (albeit in minute quantities) in commercial monomers. All the results have been summarized in Figure 7.

Incorporation of phenolic additives into polycyanurate networks. The use of monofunctional phenols [9] can lead to difunctional junctions in the network and even to dead chain ends. Increasing amounts of monofunctional phenols thus involve a continuous increase in the gel conversion (theoretically equal to 0.50 , see above), up to a critical conversion above which gelation can no longer occur. For sterically hindered phenols, which cannot be so easily incorporated into the network (although they still hasten the polycyciotrimerization reaction), the critical concentration $c^{*}$ increases. Furthermore, the reaction involves the liberation of a phenol which is not necessarily the same as the starting one; in fact, the best leaving group corresponds to the most acidic liberated phenol.

Polycyanurate matrices resulting from the cure of pure dicyanates monomers have excellent thermal and dielectric properties but are often very brittle. Several attempts are currently being undertaken in our group in order to improve this particular aspect (see below; [17]). All the studies rely on the use of elastomeric or thermoplastic modifiers, which are for the most part reactive oligomers bearing hydroxy 
or amino end groups. As was reported above, these compounds are likely to modify the reaction kinetics as well as the network build-up.

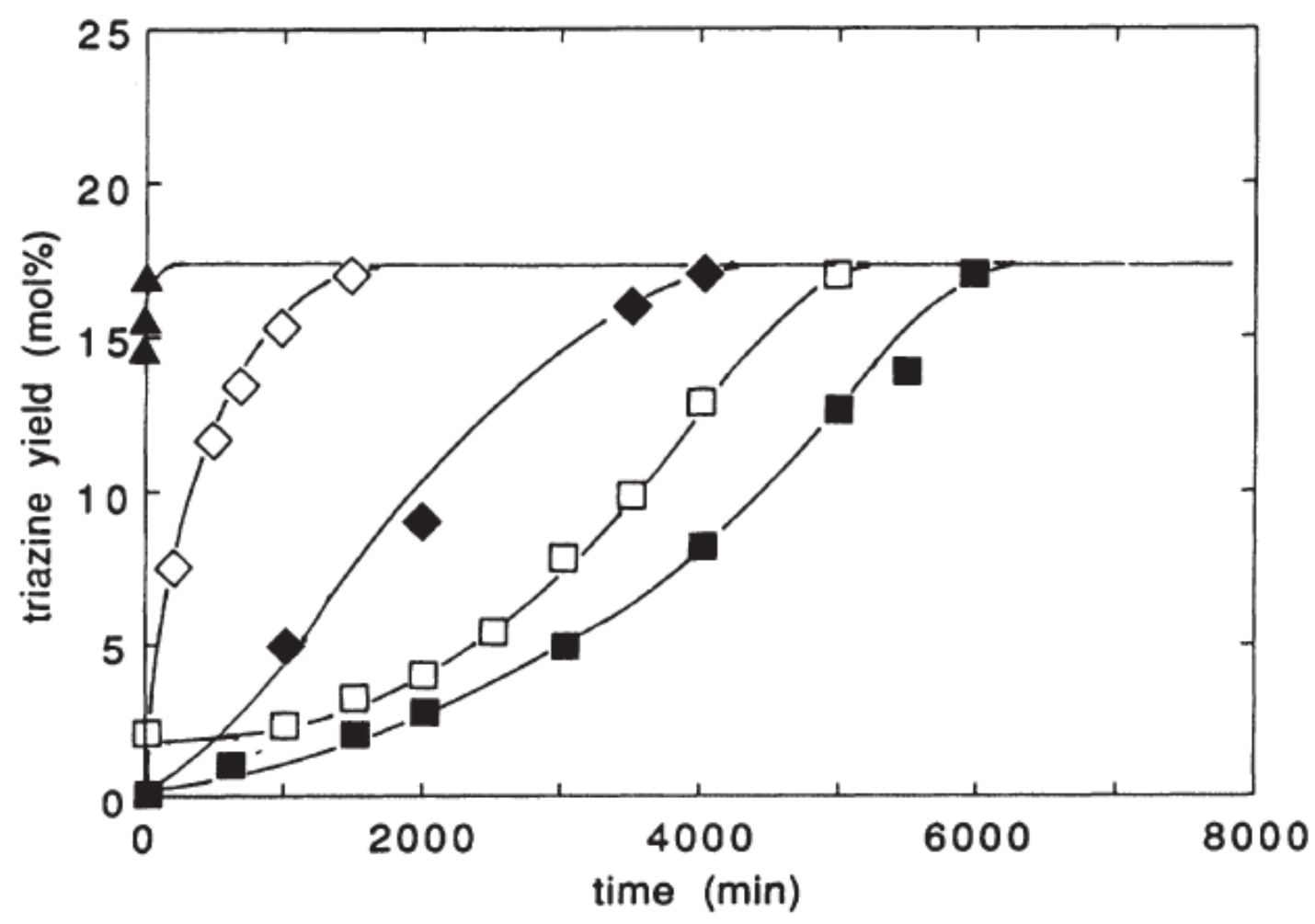

Figure 7. Time to reach the complete conversion of cyanate functions into triazine rings, for the reaction of phenol and phenylcyanate (1/1) in the absence or presence of 2 mole\% various additives $\left(T_{\mathrm{i}}=70^{\circ} \mathrm{C}\right)$. $\square$, without additive; $\square, 2$ mole\% triazine; $\diamond, 2$ mole\% iminocarbonate; $\diamond, 2$ mole\% triethylamine; $\boldsymbol{\Lambda}, 2$ mole\% aniline [9].

As part of our work on the toughening of cyanate matrices, we have studied [17] the influence of phenolic thermoplastic additives on the isothermal cyclotrimerization rate. Figure 8 displays the conversion versus reaction time curves for neat dicyanato 4,4'-diphenylethane (DPEDC) and for blends with two polyethersulfone (PES) additives. One of them is a non-functional oligomer (PES 4100P, ICI) that does not modify the reaction kinetics at all. Conversely, the other additive, which bears phenolic groups (PES 5003P, ICl), strongly increases the rate of curing process. At $180^{\circ} \mathrm{C}$, the conversion does not reach $x=1$ because of vitrification. In this case maximum conversion is lower for the blend based on PES 5003P simply as a result of better miscibility. This can be an indirect consequence of the reaction between the additive and some cyanate functions but is not a real change in the cyclotrimerization kinetics and mechanism.

In conclusion, the addition of phenolic compounds to dicyanate monomers can promote the polycyclotrimerization reaction, even in the absence of any organometallic co-catalyst and, particularly, if traces of triethylamine are present. Moreover, one must keep in mind that these phenols can be incorporated into the network and can modify the crosslink density and the gel fraction at $x=1$. Finally, nonylphenol is the most widely used phenolic modifier and, because of its rather low acidic character, should have a very strong effect on the structure of the resulting networks. 


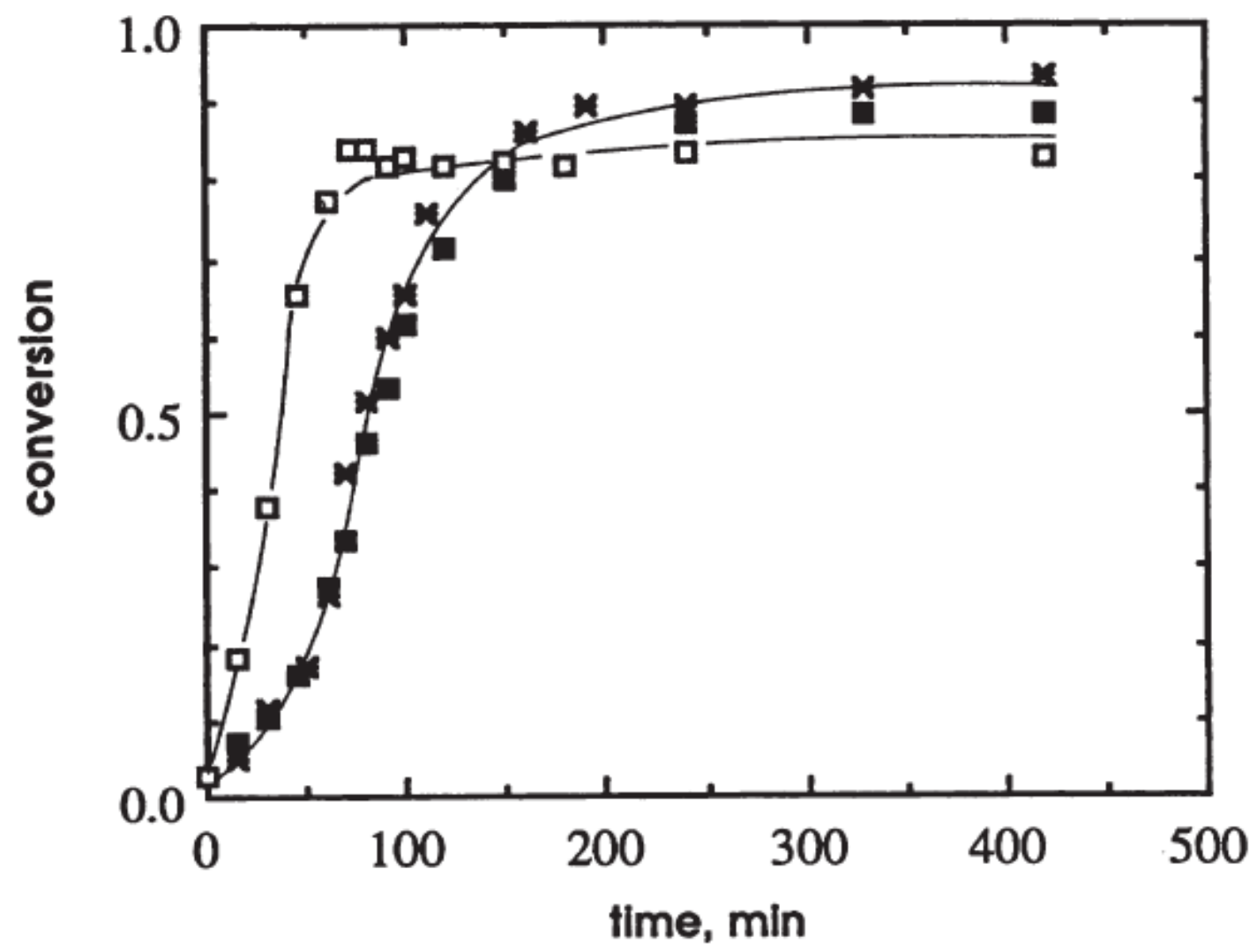

Figure 8. Effect of PES additives on the $x$ versus $t$ curve $\left(T_{\mathrm{i}}=180^{\circ} \mathrm{C}\right) ; *$, neat DPEDC; $\mathbf{\square}, 15 \%$ bw PES 4100P/DPEDC; $\square, 15 \%$ bw PES 5003P/DPEDC blend.

\subsection{Effect of alcohols and amines}

Most commercial oligomeric additives bear reactive chain ends. Their ability to react with the matrix is often of great interest since the effect is to improve the adhesion between phases in the case of a biphasic material, and in any case they ensure a chemical linkage between the modifier and the network.

In a recent work [18], we investigated the polycyclotrimerization of DPEDC in the presence of various amounts of two types of commercial thermoplastic additive (Scheme 6).<smiles>Nc1ccc(C(=O)CCCCOC(=O)c2ccc(N)cc2)cc1</smiles>

Polamine $650(n \approx 8)$ and $1000(n \approx 12)$ (Air Products)

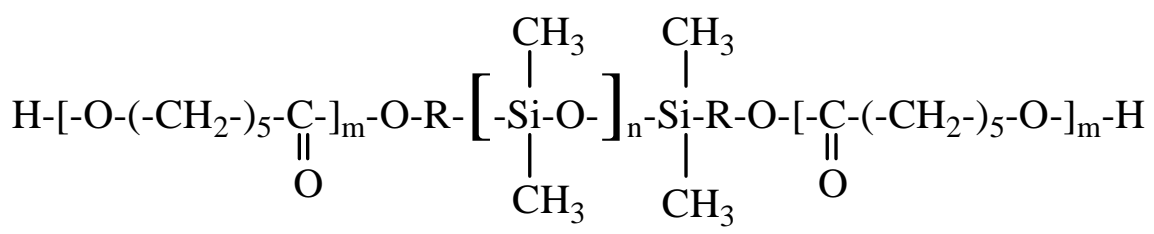

Tegomer HSi6420 ( $m \approx 9 ; n \approx 30)$ (Goldschmidt)

\section{Scheme 6}


Cao et al. [17] also studied the reinforcement of cyanate matrices by butadiene-acrylonitrile copolymers (Hycar from BF Goodrich) and, in particular, used an amino-terminated oligomeric rubber (Scheme 7). The amine used to end cap this oligomer is thus a secondary aromatic amine with a bulky substituent, i.e. it displays low reactivity towards cyanates (Unilink 4200 from UOP) (Scheme 8).<smiles>[R12]N(CC)CCCC(C)([R]C(C)(C#N)CCC(=O)OCC)C#N</smiles>

where

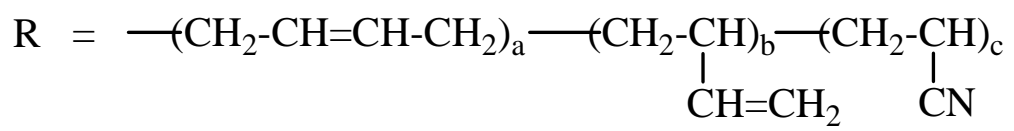

and<smiles>[R][X]c1ccc(Cc2ccc(NCCCCC)cc2)cc1</smiles>

Scheme 7

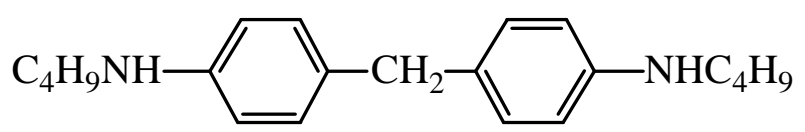

Scheme 8

All oligomers are initially miscible (compatible) in any proportion with DPEDC. The mixtures were subjected to DSC preliminary studies, which revealed that the polymerization exotherm was observed at various temperatures depending on the nature of the chain ends (heating rate $q=10 \mathrm{~K} / \mathrm{min}$ ): $\sim 130^{\circ} \mathrm{C}$ for primary aryl amine (Polamine); $\sim 220^{\circ} \mathrm{C}$ for the hydroxyl-terminated Tegomer; and $\sim 250^{\circ} \mathrm{C}$ for secondary aryl amine (Hycar).

The values of $T_{\max }$ associated with all functional oligomers are nevertheless well below the temperature associated with the pure monomer $\left(290^{\circ} \mathrm{C}\right)$. This indicates a catalytic behavior for both hydroxyl and amine groups, which is stronger in the case of Polamine. More precisely, since alcohols are less reactive than primary amines towards cyanates, their adduct, iminocarbonate, forms at higher temperature than isourea. As the cyclotrimerization also occurs at a higher temperature with hydroxylated oligomers, this would tend to confirm that the accelerating species are actually the addition compounds and not their parent alcohol or amine. This hypothesis is supported by the fact that the polymerization peak observed in DSC is always asymmetrical, with a shoulder on the low temperature side whose height is roughly proportional to the amount of hydrogen active compound; this shoulder could well be associated with the isourea or iminocarbonate formation. This was further confirmed by FTIR observations (see below).

When the amino-terminated Hycar oligomer was used as a modifier [17], we found the same type of trimerization promotion as that observed with phenolic PES (see above). Hycar not only bears reactive chain ends, but also contains $\sim 10 \%$ free diamine (Unilink 4200) left from its synthesis. In Figure 9, we have plotted the conversion versus time curves obtained for pure DPEDC, its blend with $15 \%$ bw aminoterminated Hycar and a 1.74\% Unilink 4200/DPEDC blend which simulates the excess free Unilink 4200 
in a $15 \%$ Hycar blend. It is noticeable that the Unilink 4200/DPEDC mixture reacts faster than neat DPEDC but slower than the blend with Hycar, especially at conversions above 0.6. This should be explained by combining the effect of Hycar itself with both additives leading to isourea linkages having a catalytic effect on the polycyclotrimerization reaction.

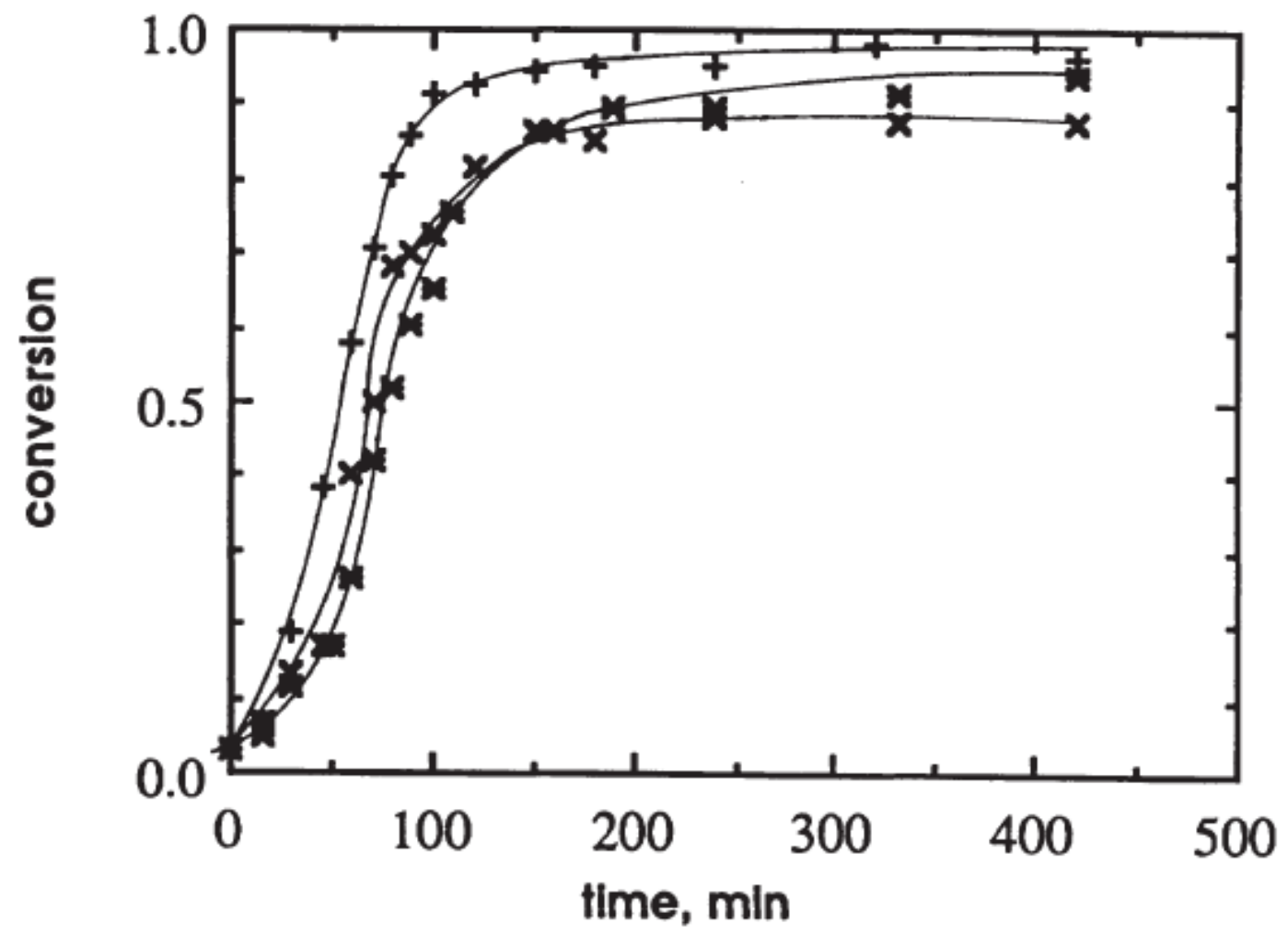

Figure 9. Increase in conversion with time for neat DPEDC and for its blends with Hycar and Unilink $4200\left(T_{\mathrm{i}}=180^{\circ} \mathrm{C}\right) ; *$, neat DPEDC; $\boldsymbol{+}, 15 \%$ bw Hycar/DPEDC blend; $\boldsymbol{X}, 1.74 \%$ bw Unilink 4200/DPEDC blend.

The curing process of the blends of DPEDC with Polamine or Tegomer was also examined [18], and in this case we tried to point out more precisely the different reactions involved. Such a study was easier because a larger quantity of reactive oligomers was used, with the aim of preparing rubber thermosets: a typical dicyanate/oligomer ratio was $1 / 1 \mathrm{bw}$. Referring to the DSC preliminary experiments, the mixtures were precured isothermally at a rather low temperature $\left(60^{\circ} \mathrm{C}\right.$ for amino-terminated oligomers, and $130^{\circ} \mathrm{C}$ for Tegomer HSi6420), since we expected to observe initially the condensation of the cyanate function with the oligomer end group. The networks were then postcured at higher temperatures (typically $200^{\circ} \mathrm{C}$ ). The evolutions of the systems as a function of time and temperature were at the same time monitored by FTIR spectroscopy. In fact, it appears that cyclotrimerization occurs as soon as the precure starts, i.e. at $60^{\circ} \mathrm{C}$ in the presence of Polamine. An increase in the cure temperature only enhances slightly its rate (Figure 10). The maximum values associated with triazine and $\mathrm{C}=\mathrm{N}$ were arbitrarily taken equal to 1 . The peak at $1630 \mathrm{~cm}^{-1}$ was attributed to the isourea linkage which seems to be formed together with the triazine rings; it is impossible to dissociate both reactions, probably because the isourea is too strong a catalyst for cyclotrimerization. However, it is still possible 
to control the increase in viscosity of the system by adjusting the cure cycle. The same results were observed with the hydroxy-terminated Tegomer, though at higher temperatures.

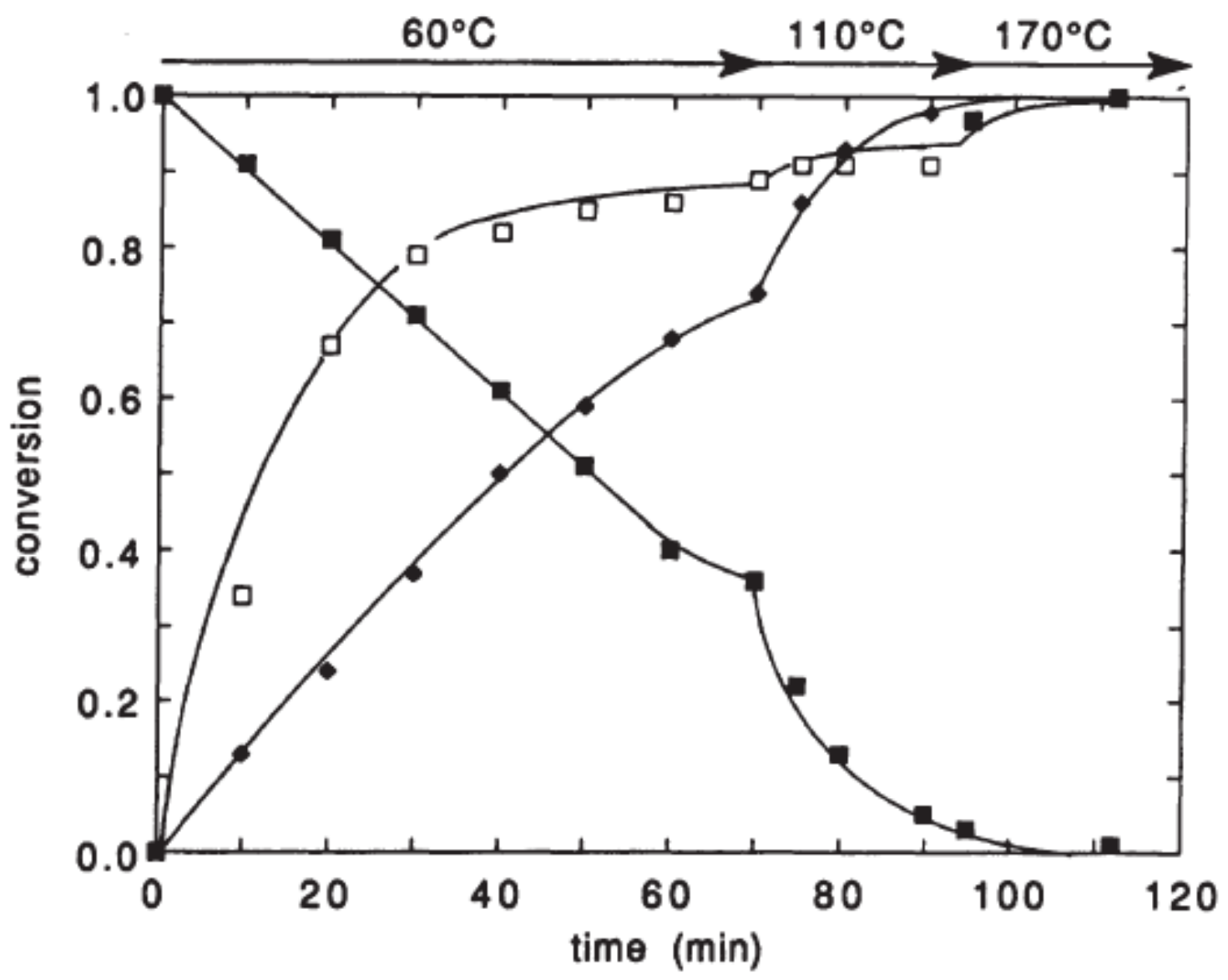

Figure 10. Evolution of the FTIR absorbance peaks associated with cyanate $\left(2270 \mathrm{~cm}^{-1}, \mathbf{\square}\right)$; $\mathrm{C}=\mathrm{N}$ (isourea ?) $\left(1630 \mathrm{~cm}^{-1}, \square\right)$; and triazine $\left(1365 \mathrm{~cm}^{-1}, \diamond\right)$ as a function of time and temperature for the cure of DPEDC modified by Polamine $650\left(\mathrm{OCN} / \mathrm{NH}_{2}=3\right)$ (reference peak: $\mathrm{CH}_{2}, 2853 \mathrm{~cm}^{-1}$ ).

\section{Cyanate ester/epoxy networks}

Little published work relates the reaction pathway between epoxy and cyanate groups to the network properties. The main reason for this is the relative novelty of these products as compared to epoxyamine networks for which large amounts of data are available in the literature.

\subsection{Studies on monofunctional compounds}

The most important studies on the cyanate-epoxy co-reaction have been made by Bauer et al. $[19,20]$ and Shimp et al. [21]. In 1989, Bauer et al. proposed a complex reaction mechanism, which was later confirmed by Shimp in 1992. A detailed discussion is presented by Bauer and Bauer in chapter 3.

Both teams based their experiments on model compounds: Bauer used 4-chlorophenyl cyanate (CI.PCy) and phenyl glycidyl ether (PGE), while Shimp used 4-cumylphenyl cyanate (CPCy) and PGE. CPCy is an exact analog of bisphenol A dicyanate (DCBA) but is monofunctional. In such systems, gelation cannot occur and the material remains soluble until the end of the reaction. Therefore, chromatographic analyses, chemical titration and liquid NMR can be used to identify the structure of the reaction products. 
Bauer et al. investigated the influence of the following parameters on the reaction path:

- temperature: between $80^{\circ} \mathrm{C}$ and $230^{\circ} \mathrm{C}$

- atmosphere: reaction conducted in air or under dry nitrogen

- catalyst: copper(II) acetylacetonate, zinc octoate, N,N-dimethylaniline, N,N-dimethylbenzylamine

- ratio of cyanate/epoxy: ranging from $1 / 1$ (equimolar blend) to $1 / 18$.

HPLC analyses showed that the only significant parameter that influences the reaction products is the temperature; the catalyst, the atmosphere and the stoichiometric ratio do not alter the chemical path, but only the proportion of each reaction product. The reaction proceeds via six main steps (Figure 11).

(i) trimerization of the cyanate esters and formation of a trimer is always the first step

(ii) insertion of the glycidyl ether groups into the cyanurate ring

(iii) isomerization of alkylcyanurates into alkylisocyanurates

(iv) reaction of glycidyl ether with alkylisocyanurate and formation of oxazolidinone

(v) elimination of substituted phenol from the alkyl structure

(vi) addition of glycidyl ether and phenol.

Therefore, the direct reaction of cyanate and epoxy to yield oxazolidinone is unlikely to occur in such a system. Furthermore, the reaction of two cyanate functions to form a dimer (four-membered cycle) has not been observed. The triazine ring has a catalytic effect on the reaction between cyanate and phenol but no effect on the reaction between cyanate and epoxy.

Work carried out by Shimp et al. has brought new elements to the chemical path. They have compared the reaction between cyanate monomer CPCy and PGE to the reaction between trimer (tris (4cumylphenyl) cyanurate) and PGE: more oxazolidinone rings are formed in the first case. In both cases, Shimp et al. examined the effects of catalyst and again more oxazolidinone is found using the monomer instead of its trimer.

From the authors' point of view, this indicates that part of the oxazolidinone is produced directly from monomers in contrast to the insertion/isomerization/ring cleavage route. The highest level of oxazolidinone groups is obtained for the uncatalyzed CPCy/PGE system. However, catalysis by titanium chelates yields very similar products; furthermore, it can be seen that oxazolidinones are produced directly from monomers in such a system and at room temperature. As a consequence, for difunctional monomers this reaction can increase the molar mass between crosslinks $\left(M_{c}\right)$.

All these structures are clearly evidenced by FTIR spectroscopy which is the main technique used by Shimp and co-workers. The comparison between the various products is made by calculating the ratio of cyanurate, isocyanurate and oxazolidinone peaks heights to that of the methyl $\mathrm{C}-\mathrm{H}$ peak height which is an internal standard. The infrared characteristic absorptions and the ${ }^{13} \mathrm{C}$ NMR chemical shifts are listed in Table $2 .{ }^{13} \mathrm{C}$ NMR is also a very powerful technique, well adapted to the study of cyanates and epoxies. 
i)<smiles>C[Al]Oc1nc(O[Al])nc(O[Al])n1</smiles>

ii)<smiles>CCCCCO[Al]COc1nc(O[Al])nc(O[Al])n1</smiles>

iii)<smiles>[AlH2]Oc1nc(O[AlH2])nc(O[AlH2])n1</smiles><smiles>CCCCCCCCn1c(=O)n([AlH2])c(=O)n([AlH2])c1=O</smiles>

iv)<smiles>[14CH3]N1CC(CO[Al])OC1=O</smiles>

v)<smiles>CCC(CO[Al])O[Al]CC=CCO[Al][Al]O</smiles>

vi)

$$
\begin{aligned}
& \mathrm{Ar}^{\prime \prime}-\mathrm{O}-\mathrm{CH}_{2}-\mathrm{CH}_{\mathrm{O}}^{\mathrm{CH}}-\mathrm{CH}_{2}+\mathrm{Ar}^{\prime}-\mathrm{OH} \longrightarrow \mathrm{Ar}^{\prime}-\mathrm{O}-\mathrm{CH}_{2}-\underset{\mathrm{I}}{\mathrm{CH}}-\mathrm{CH}_{2}-\mathrm{O}-\mathrm{Ar}^{\prime \prime} \\
& \mathrm{Alk}=-\underset{\mathrm{CH}}{-\mathrm{CH}}-\mathrm{CH}_{2}-\mathrm{O}-\mathrm{Ar}^{\prime \prime} \\
& \mathrm{O}-\mathrm{Ar}^{\prime}
\end{aligned}
$$

Figure 11. Reaction scheme proposed between cyanate esters and epoxides $[19,20]$. 
Table 2. FTIR and ${ }^{13} \mathrm{C}$ NMR spectral assignments for the compounds involved in the reaction between cyanate and epoxy

\begin{tabular}{|c|c|c|}
\hline Chemical group & FTIR wavenumber $\left(\mathrm{cm}^{-1}\right)^{\mathrm{a}}$ & ${ }^{13}$ C NMR shift (ppm) ${ }^{b}$ \\
\hline Methyl & 2875 & 30.8 \\
\hline Cyanate $\mathrm{C} \equiv \mathrm{N}$ & 2270 & 108.9 \\
\hline Cyanate $\mathrm{C} \equiv \mathrm{N}$ & 2235 & \\
\hline Oxazolidinone $\mathrm{C}=\mathrm{O}$ & 1753 & 154 \\
\hline Isocyanurate $\mathrm{C}=\mathrm{O}$ & 1696 & 149 \\
\hline Triazine ring & 1566 & 173.5 \\
\hline Isocyanurate & 1457 & \\
\hline Cyanurate -O- & 1369 & \\
\hline Aromatic ether & 1244 & \\
\hline Polyether -O- & 1132 & \\
\hline Epoxide & 916 & $44.1-50.1$ \\
\hline
\end{tabular}

${ }^{a}$ From reference 21.

${ }^{b}$ From our laboratory.

\subsection{Studies on difunctional compounds}

(i) Influence of catalysts. Shimp and Wentworth [21] studied the behavior of BADGE/DCBA systems with and without a catalyst. Previous results obtained on monofunctional systems were confirmed: the same chemical groups (triazine, isocyanurate, oxazolidinone) are observed on FTIR spectra and they found more chain-extending reaction (oxazolidinone groups) for uncatalyzed and titanatecatalyzed networks. These networks exhibit higher mechanical strength and strain-at-break as compared to networks catalyzed by copper(II) acetylacetonate. Other properties $\left(T_{\mathrm{g}}\right.$, moisture absorption) show only little difference.

We have also performed some experiments on BADGE (DER 332)/DCBA (B10) equimolar blends and looked for the influence of 2-ethyl-4-methylimidazole (EMI), a typical catalyst for epoxies as compared to the influence of copper(II) acetylacetonate, $\mathrm{Cu}(\mathrm{acac})_{2}$, a typical catalyst for cyanate. As can be seen on the thermograms reported in Figure 12 , the temperature at the peak maximum decreases by $30^{\circ} \mathrm{C}$ when BADGE is introduced into DCBA. The reaction starts near $250^{\circ} \mathrm{C}$ in both cases but the exothermic peak is narrower in the BADGE/DCBA system. EMI does not have a strongly catalytic effect because the temperature at the peak maximum is only shifted by $20^{\circ} \mathrm{C} . \mathrm{Cu}(\mathrm{acac})_{2}$ shows a more pronounced effect: two exothermic peaks are observed and the reaction starts near $200^{\circ} \mathrm{C}$. However, we found that the catalytic effect of $\mathrm{Cu}(\mathrm{acac})_{2}$ is greatly reduced in BADGE/DCBA systems as compared to pure DCBA in which the reaction starts near $100^{\circ} \mathrm{C}$. 


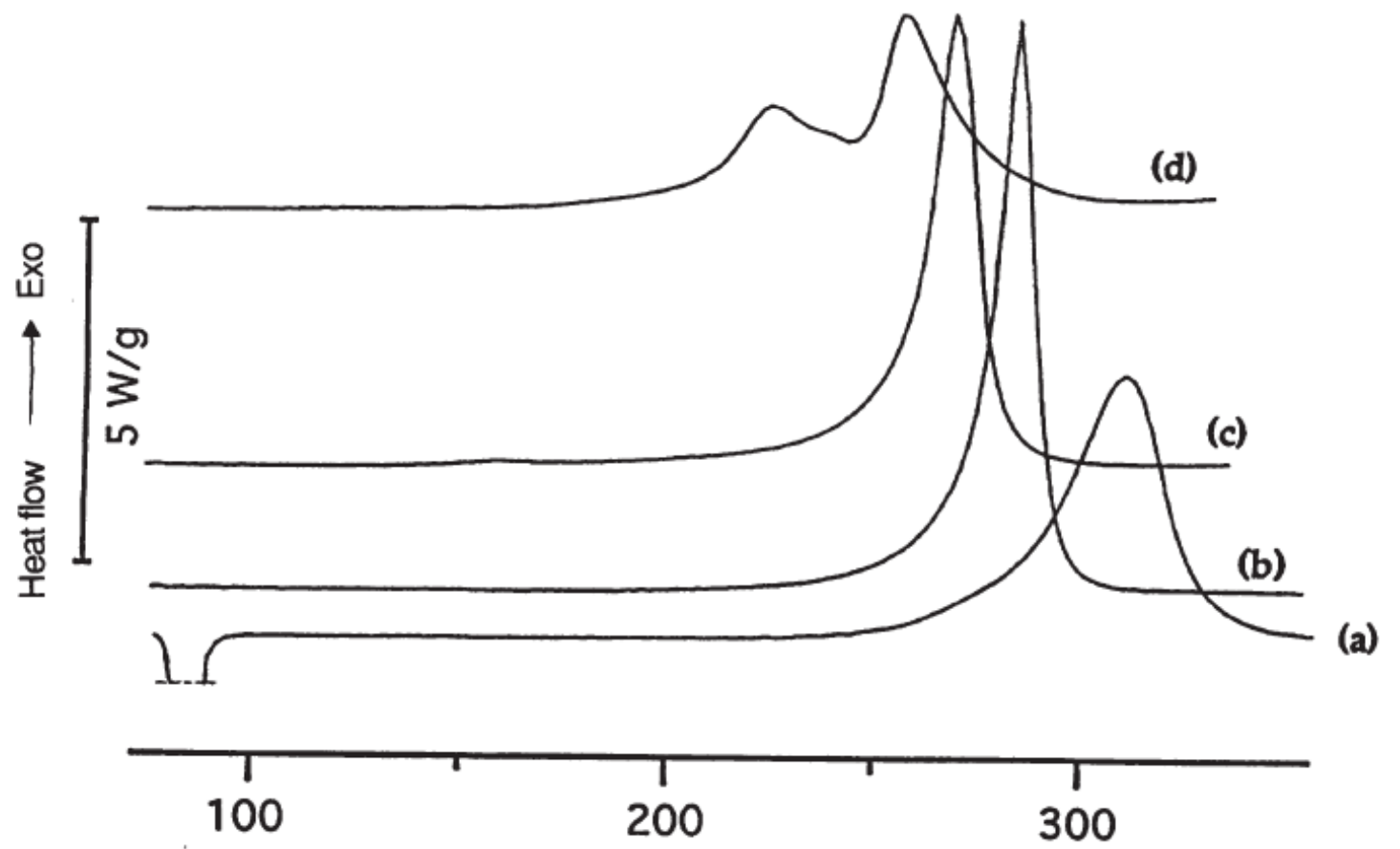

Temperature $\left({ }^{\circ} \mathrm{C}\right)$

Figure 12. Influence of a catalyst on DSC scans, heating rate $=10 \mathrm{k} / \mathrm{min}$. (a) DCBA; (b) BADGE/DCBA; (c) BADGE/DCBA/1\%EMI; (d) BADGE/DCBA/200 ppm Cu(acac) $2+2$ phr nonylphenol.

The relation between $T_{\mathrm{g}}$ and the residual reaction is not modified by EMI (Figure 13); however the fully cured networks (defined as displaying no residual cyanate and epoxy functions by FTIR) are different. The main difference is that the network cured with EMI has nearly 30 to $40 \%$ less oxazolidinone and also less isocyanurate than the uncatalyzed network (Figure 14). So, we suppose that the epoxy cycle follows the insertion route (step (ii), Figure 11) or reacts via the homopolymerization reaction. A similar trend was observed by Caille et al. [22,23] when they studied di-isocyanate/diepoxy/EMI mixtures.

The viscoelastic spectra of an uncatalyzed BADGE/DCBA network is compared to a pure polycyanurate network in Figure 15 . The sub- $T_{\mathrm{g}}$ relaxations are modified: a single broad relaxation is observed in the BADGE/DCBA network instead of the $\gamma$ relaxation at $-100^{\circ} \mathrm{C}$ and the $\beta$ relaxation at $0^{\circ} \mathrm{C}$ observed in pure polycyanurate. As expected, the $\alpha$ relaxation is lower in the BADGE/DCBA network, but surprisingly the rubber modulus is higher than in the pure cyanate network. This value is related to the crosslink density. Moreover, the Williams-Landel-Ferry (WLF) [24-26] equation can be used to describe the temperature dependence of the shift factor, $a_{\mathrm{T}}$, determined from the dependence of $G^{\prime}$ or $G^{\prime \prime}$ on frequency. $C_{1}{ }^{\mathrm{g}}$ and $\mathrm{C}_{2} \mathrm{~g}$, the WLF coefficients, are given in Table 3 , for the pure polycyanurate network, the BADGE/DCBA network and also a classical epoxy/amine network [26]. A high increase in both coefficients is observed as epoxy is introduced into the polycyanurate network. Generally an increase in $\mathrm{C}_{1}{ }^{\mathrm{g}}$ and $\mathrm{C}_{2}{ }^{\mathrm{g}}$ is observed as the crosslink density increases. As a consequence, these high values of the WLF coefficients lead to high values of the free volume fraction at $T_{\mathrm{g}}$ and the thermal expansion coefficient. However, molecular rearrangements and chain scissions have been observed at high temperatures in networks based on isocyanate and epoxy [22,23]. As such networks show some 
similarities with cyanate/epoxy networks, we cannot exclude the occurrence of structural changes in the network in the $T_{\mathrm{g}}$ region. Further experiments are in progress.

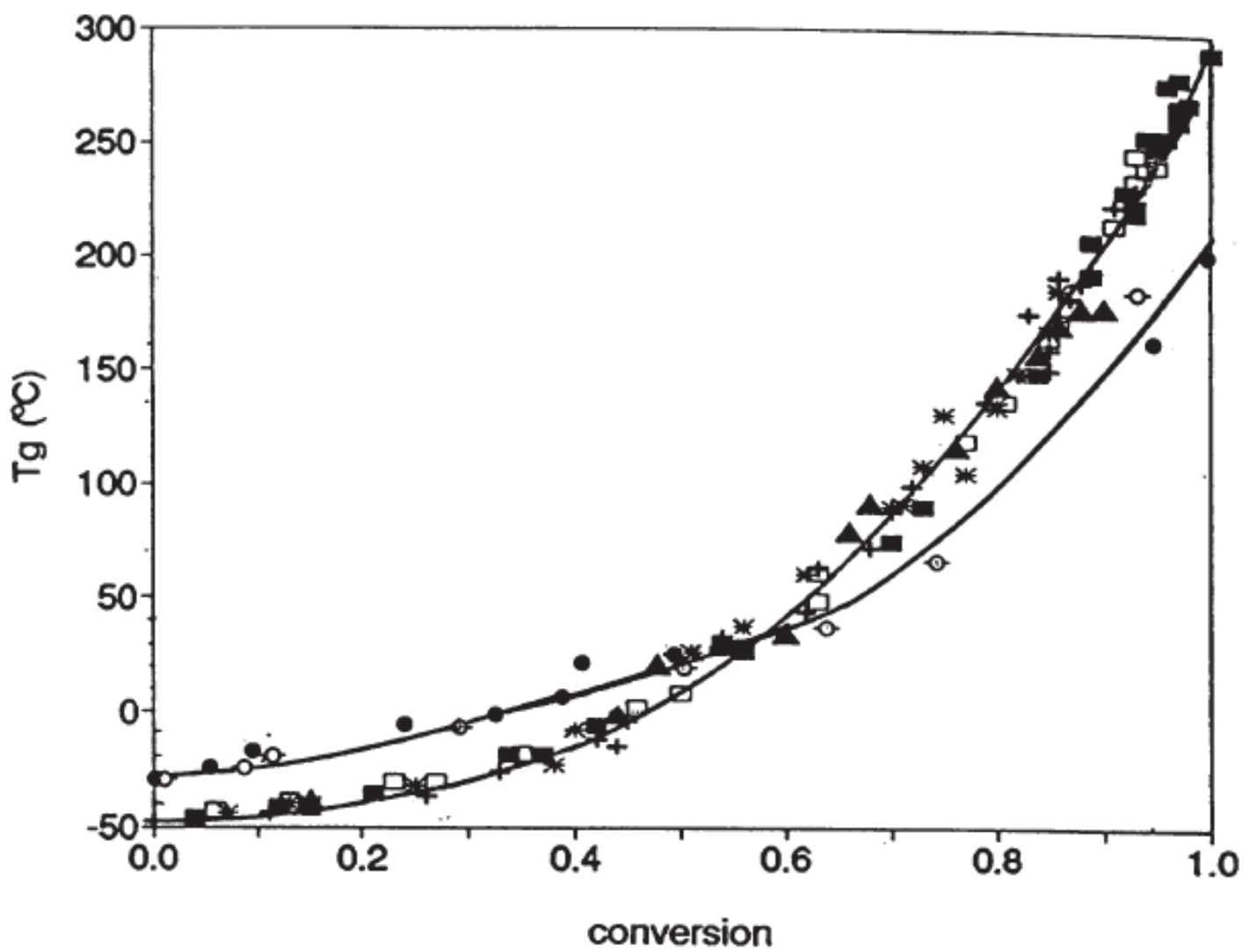

Figure 13. $T_{\mathrm{g}}$ as a function of the residual enthalpy measured by DSC. $\bullet, B A D G E / D C B A, T_{\mathrm{i}}=200^{\circ} \mathrm{C}$, O, BADGE/DCBA $/ 1 \% E M I, T_{\mathrm{i}}=160^{\circ} \mathrm{C},-, \mathrm{DCBA}, 150^{\circ} \mathrm{C}<T_{\mathrm{i}}<250^{\circ} \mathrm{C}, \boldsymbol{\Delta}, T_{\mathrm{i}}=150^{\circ} \mathrm{C} ; *, T_{\mathrm{i}}=165^{\circ} \mathrm{C}$; $\mathbf{+}, T_{\mathrm{i}}=200^{\circ} \mathrm{C} ; \square, T_{\mathrm{i}}=225^{\circ} \mathrm{C} ; \boldsymbol{\square}, T_{\mathrm{i}}=250^{\circ} \mathrm{C}[13]$. 


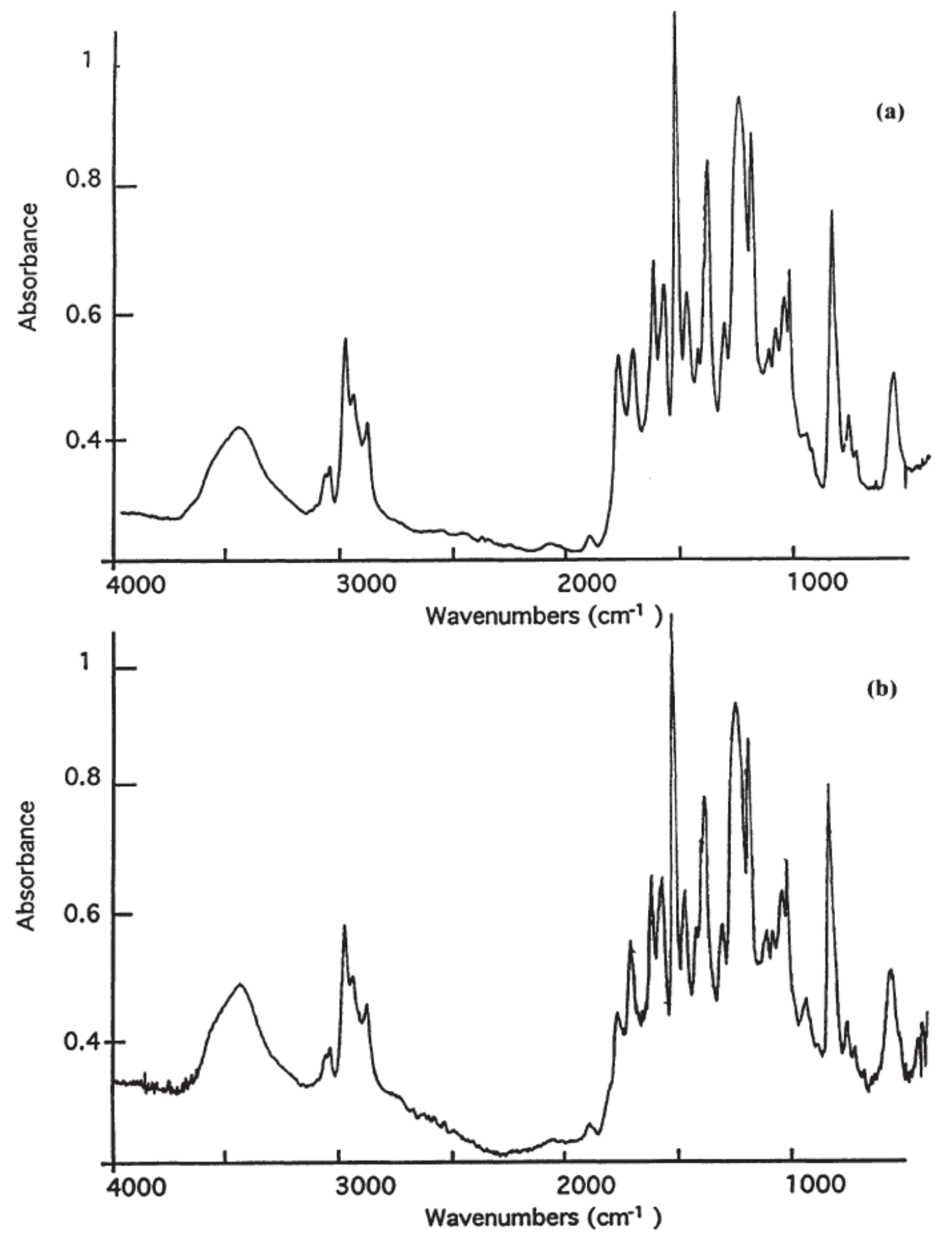

Figure 14. Infra-red spectra for: (a) BADGE/DCBA; (b) BADGE/DCBA/1\%EMI.

(ii) Influence of epoxy prepolymer structure. Shimp [21] examined the influence of a high molar mass diglycidyl ether of tetrabromobisphenol A (epoxy equivalent $(e e)=650$ ) on the network properties. $T_{\mathrm{g}}$ remains identical to that of BADGE/DCBA networks $\left(T_{\mathrm{g}}=200^{\circ} \mathrm{C}\right.$ by DMA): owing to the bulky bromine atoms the flexibility of the chain is reduced and therefore compensates the effect of the molar mass. Mechanical properties are good with even higher flexure moduli, and moreover all properties are 
independent of the catalyst. Gel times are shorter and oxazolidinone fractions are significantly higher than in BADGE/DCBA formulations.

(a)

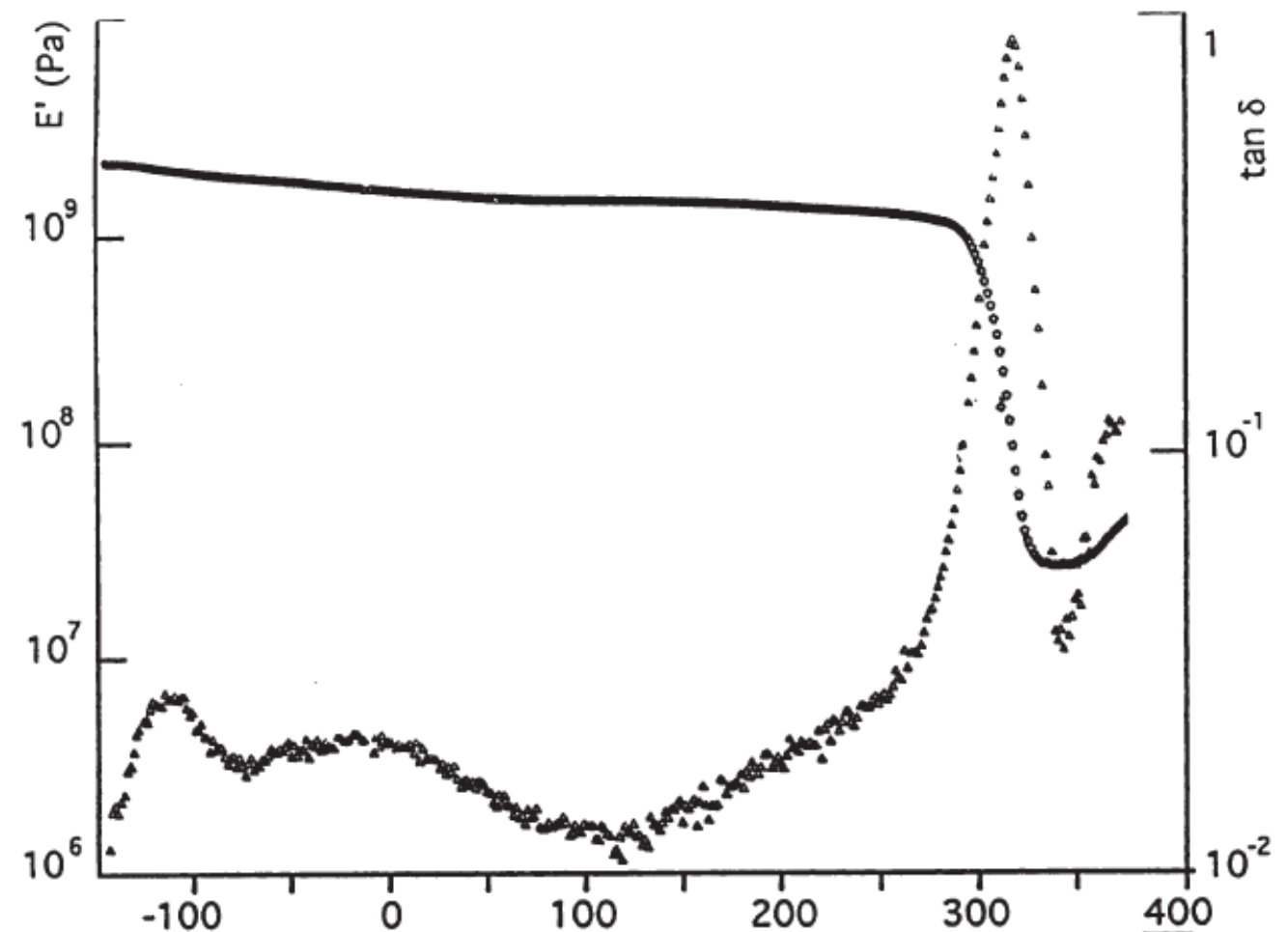

(b)

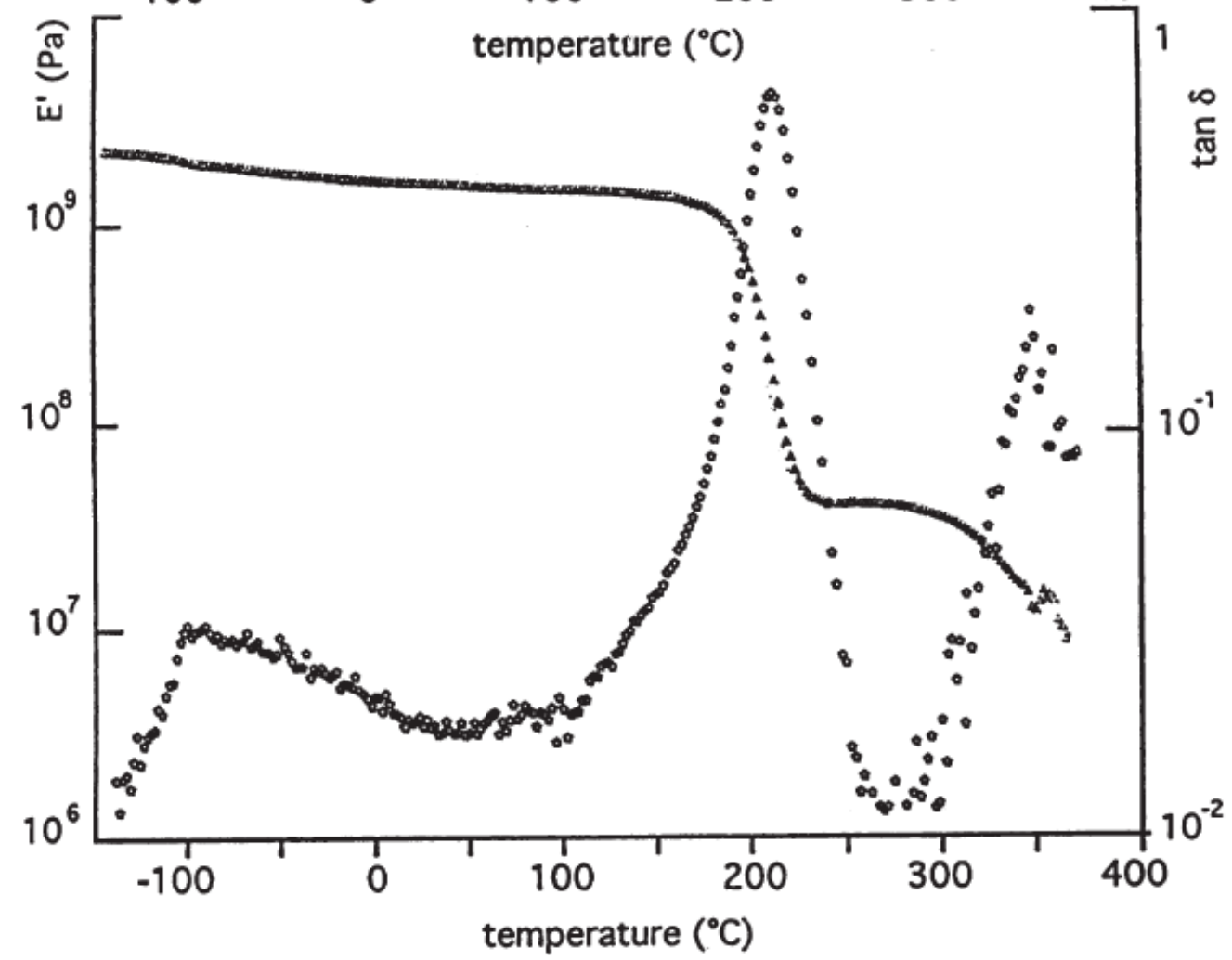

Figure 15. Viscoelastic spectra at $1 \mathrm{~Hz}$. (a) DCBA; (b) BADGE/DCBA. 
Table 3. WLF parameters and free volume characteristics of different networks

\begin{tabular}{|l|c|c|c|}
\hline & DCBA & DCBA/DER332 & $\begin{array}{c}\text { Typical epoxy } \\
\text { BADGE/3DCM }\end{array}$ \\
\hline$T_{\text {endcure }}{ }^{\circ} \mathrm{C}$ & 290 & 250 & 190 \\
$T_{\mathrm{g}}{ }^{\circ} \mathrm{C}(\mathrm{DSC})$ & 283 & 190 & 185 \\
$T_{\text {ref }}{ }^{\circ} \mathrm{C}$ & 293 & 204 & 194 \\
$C_{1}{ }^{\mathrm{g}}$ & 9.9 & 14 & 9.2 \\
$C_{2}{ }^{\mathrm{g}}$ & 35 & 68 & 43 \\
$f_{\mathrm{g}} / \mathrm{B}\left(10^{-2}\right)$ & 4.4 & 3.1 & 4.72 \\
$C_{\mathrm{f}} / \mathrm{B}\left(10^{-3} / \mathrm{K}\right)$ & 1.25 & 0.45 & 1.1 \\
\hline
\end{tabular}

3DCM, 4,4'-diamino-3,3'-dimethyldicyclohexyl methane.

(iii) Influence of the epoxy prepolymer concentration. The effect of the stoichiometric ratio cyanate/epoxy has been studied by Bauer et al. [27]; the uncatalyzed network changes from a pure polycyanurate into an oxazolidinone when the amount of BADGE is increased (Figure 16), and a maximum of isocyanurate cycles are formed for equimolar proportions. This is discussed in detail in chapter 4. The conversion at the gel point increases with an increase in the initial BADGE amount; however, the gel times are only slightly dependent on the composition of the initial mixture. As for pure cyanate trimerization, the main factor for time behavior is the purity of monomers.

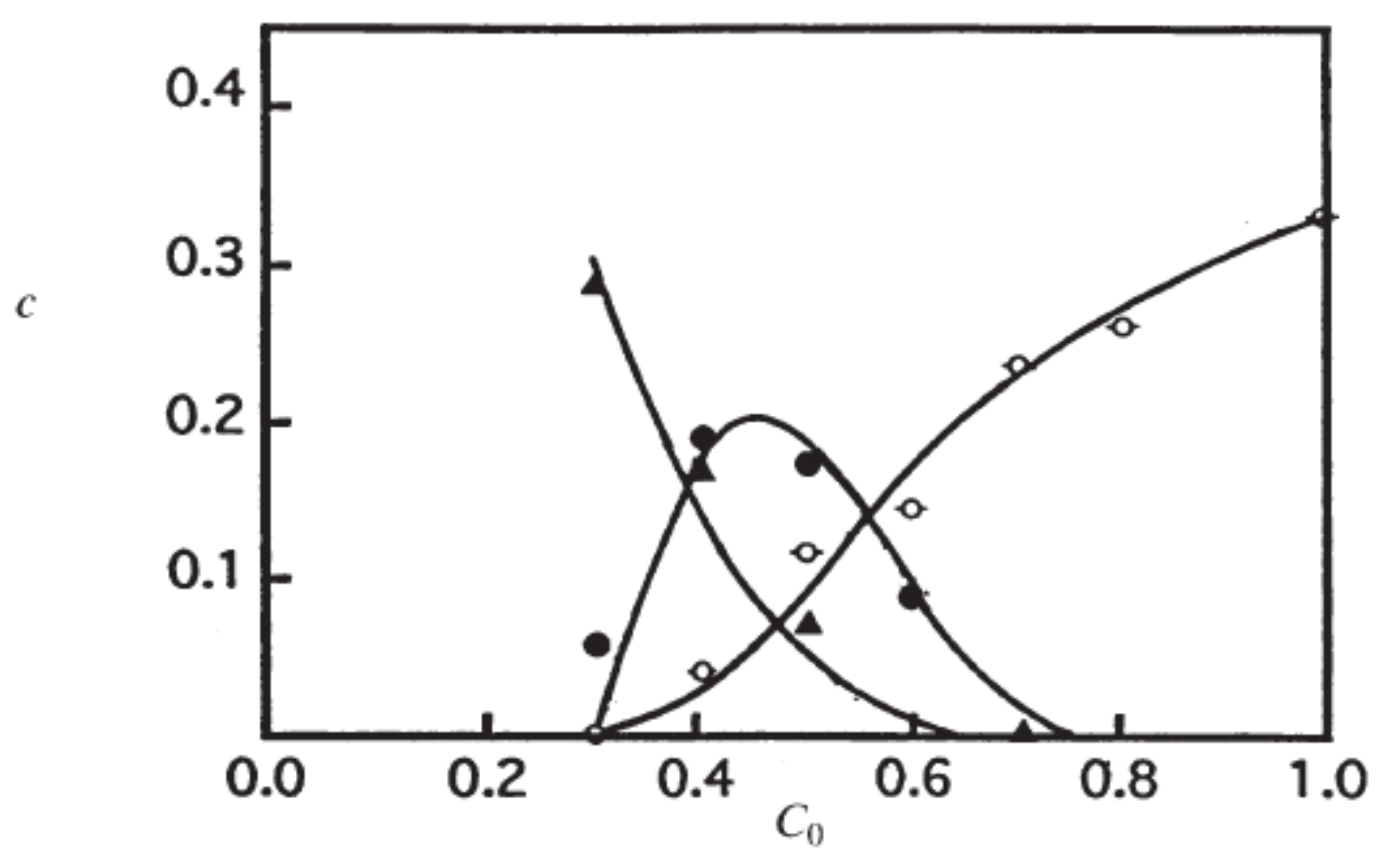

Figure 16. Influence of the initial-OCN content $\left(C_{0}\right)$ on the normalized concentration of structural elements at full conversion $(c)$. Calculated values: (-). Experimental value by IR: $O$, triazine; isocyanurate; $\mathbf{\Lambda}$, oxazolidinone [27].

Heat deflection temperatures (HDT) and dielectric constant $\left(D_{k}\right)$ have been measured as a function of DCBA concentration by Shimp and coworkers, who found higher HDT and slightly lower $D_{k}$ for brominated resins, particularly for low cyanate-ester concentrations. 


\section{Miscellaneous networks}

\subsection{Diluents}

Few results on the influence of reactive diluents have been published. Cozzens et al. [28] studied a series of DCBA networks where the degree of crosslinking was varied by addition of CPCy in order to relate the laser ablation energy to the crosslink density $n$ : it increases with $n$.

Papathomas and Wang [29] prepared polycyanurate networks based on blends of fluorinated DCBA and dinonylphenol cyanate, a non-polar reactive diluent. The crosslink density is reduced and $T_{\mathrm{g}}$ reaches $140^{\circ} \mathrm{C}$ when $20 \%$ of diluent is used. For the authors, the advantage of this system is to allow curing at low temperature $\left(180^{\circ} \mathrm{C}\right)$ compared to pure polycyanurates while maintaining low dielectric loss properties.

\subsection{Cyanate-bismaleimide networks}

As in cyanate/epoxy networks, the co-reaction between cyanate-ester and maleimide functional groups is not well described in the literature, although commercial products are available. These products called BT resins (bismaleimides-triazine) have been developed by Mitsubishi Gas Oil Chemical. The proposed chemical path is reported in Figure 17a [30], but this pyrimidine-type structure has not been confirmed experimentally [31]. Functionalized cyanate-esters have been synthesized by Hamerton et al. [31,32] with the aim of using them as reactive diluents to improve processability with BMIs and to toughen the matrix. Linked interpenetrating networks (LIPNs) are produced from the reaction between these two different monomers. It seems that co-reaction occurs by means of an 'ene'/Diels-Alder reaction (see Figure 17b), yielding densely crosslinked polymer with high $T_{\mathrm{g}}\left(>350^{\circ} \mathrm{C}\right.$ by DMTA). The high $T_{\mathrm{g}}$ of the resulting networks allows the incorporation of inherently tough, oligomeric components (BMI or functionalized cyanate ester), which will increase fracture toughness whilst maintaining acceptable $T_{\mathrm{g}}$.

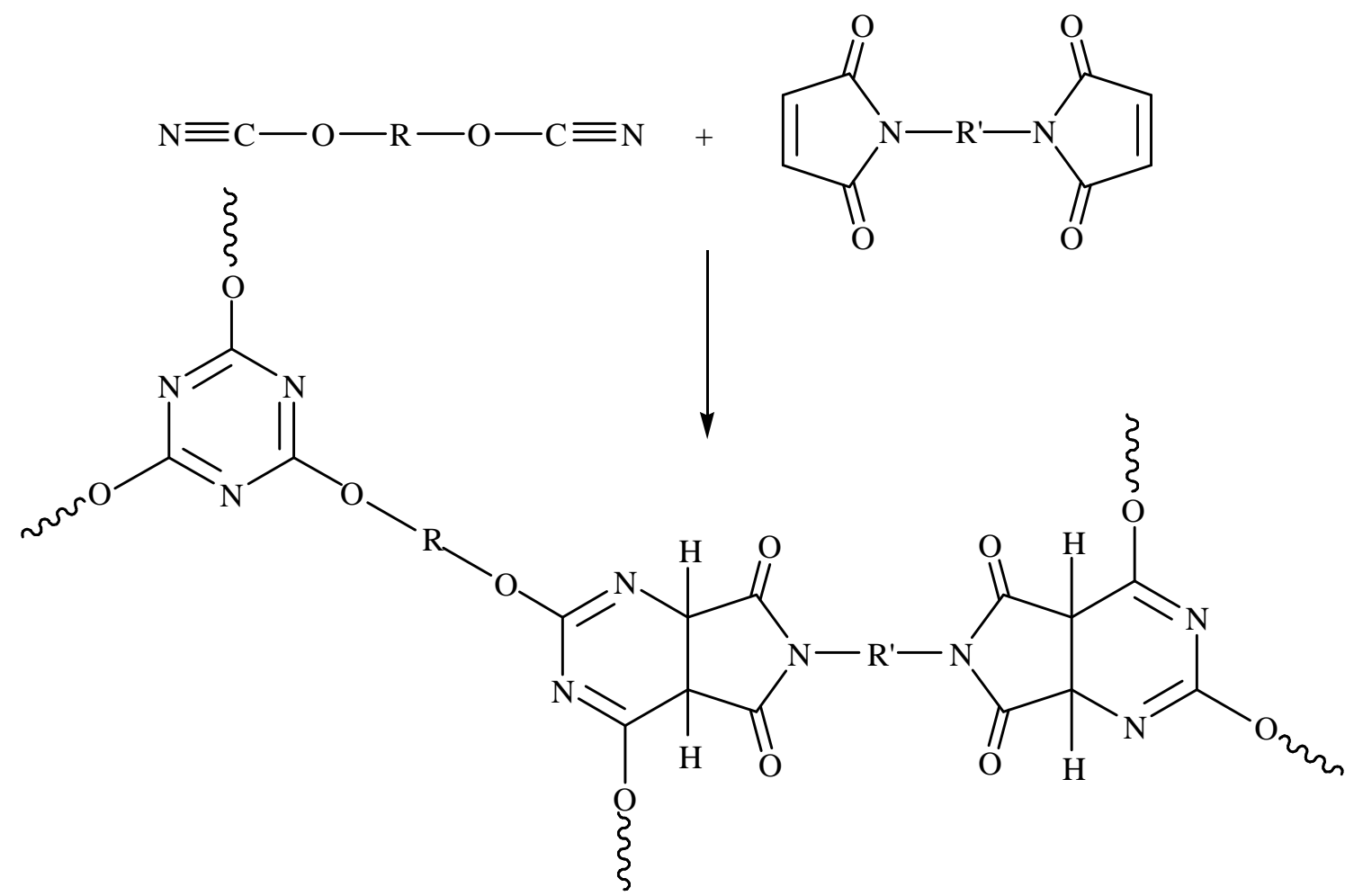

Figure 17(a). Proposed reaction paths for bismaleimide/triazine systems, BT resins [30]. 
<smiles>C=CCc1cc([Al])ccc1ON</smiles>

$\Delta$

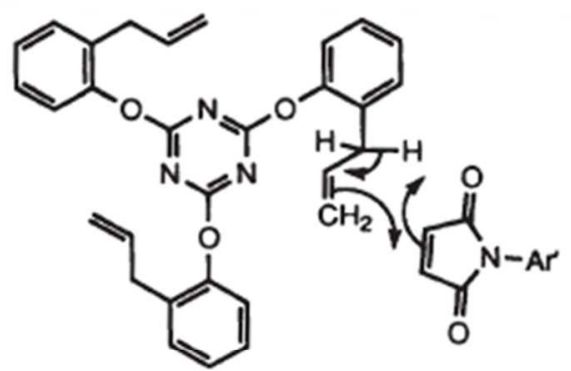<smiles>[Te][Te]</smiles><smiles>[Y]Oc1nc(O)nc(Oc2cccc3c2C=CC(CC2CC(=O)N([Y])C2=O)C2C(=O)N([Y])C(=O)C32)n1</smiles>

Diels-Alder (+ BMI)<smiles>[3H][3H]</smiles>

'Ene' reaction<smiles>COc1nc(OCCCCCC(C)(C)C)nc(Oc2ccccc2C=CCCC2CC(=O)N([Al])C2=O)n1</smiles>
Aromatization<smiles>[Y]N1C(=O)CC(CC2Cc3c4cccc3C3C(=O)N([Al])C(=O)C(OC)=NC(O[13CH3])=NC(=C23)O4)C1=O</smiles>

'Ene'/Diels-Alder product and homopolymers

Further cross-linking

Figure 17(b). BMI 'ene' reaction [32].

\section{Rubber and thermoplastic-modified cyanates}

Brittle thermosets are best toughened by introduction of a rubbery (R) or a thermoplastic (Tp) dispersed phase [33-36 and references therein]. Generally, at the curing temperature, $T_{\mathrm{i}}$, the initial mixture of monomer(s) and additive is homogeneous (Figure 18). The dispersed phase results from the phase separation induced by the step-growth polymerization of the monomer(s). A sketch of the process is represented in Figure 19; it can be described as a 'chemical quench' because the chemical reaction drives the change in free energy. 
(a)

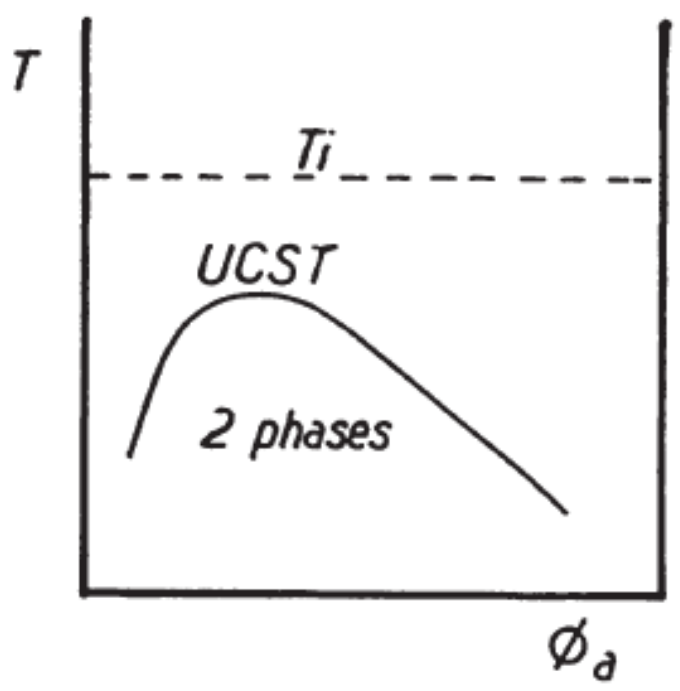

(b)

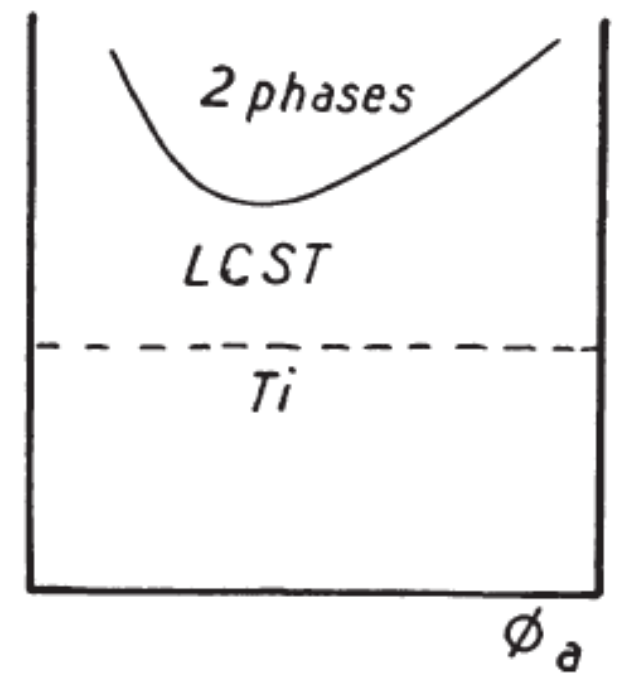

Figure 18. Binary-phase diagram, temperature, $T$ versus the volume fraction, $\Phi_{\mathrm{a}}$, of an additive dissolved in a monomer. (a) Upper critical solubility temperature behavior (UCST); (b) lower critical solubility temperature (LCST) (binodal curves).

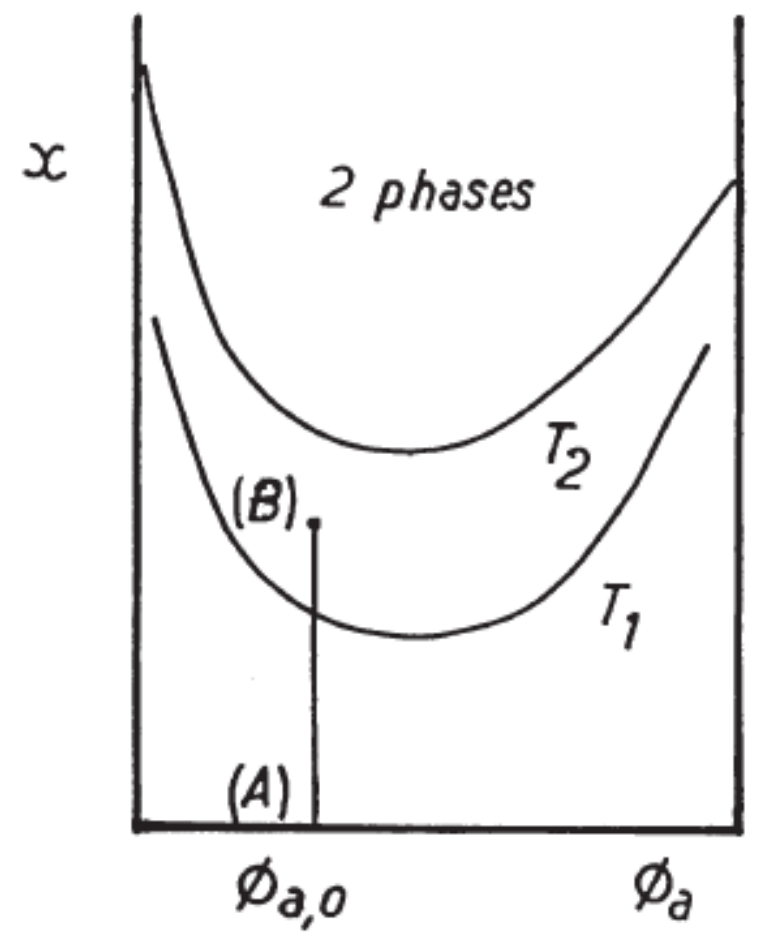

Figure 19. Binary-phase diagram, reactive group conversion, $x$, versus the volume fraction, $\Phi_{\mathrm{a}}$, of the additive. During the polymerization, the system is going from the one-phase point $A\left(\Phi_{a, 0}\right)$ to the twophase point B. $T_{2}>T_{1}$ for a UCST behavior, $T_{1}>T_{2}$ for a LCST behavior. 
Studies on the phase-separation process and on the formation of the morphology mainly focus on the rubber-modified epoxies. These studies show that the morphology formed (diameters, number and volume fraction of the dispersed spherical particles) is determined by the competing effects between phase separation and polymerization rates [37-39]. Analysis of the experimental results can give the following conclusions:

(i) The concentration of dispersed particles decreases with isothermal precuring temperature, $T_{\mathrm{i}}$

(ii) The volume fraction of dispersed phase, $V_{D}$, remains practically constant, goes through a maximum or decreases with $T_{\mathrm{i}}$

(iii) The average diameter, $\bar{D}$, of spherical particles increases with $T_{\mathrm{i}}$

(iv) $\bar{D}$ and $V_{\mathrm{D}}$ increase with the initial volume fraction of the additive, $\Phi_{\mathrm{a}, 0}$

(v) $V_{D}$ is always greater than $\Phi_{a, 0}$. This means that the dispersed phase is not formed of pure additive, $\mathrm{R}$, but also contains epoxy-amine copolymer. It can be around $50 \%$ bw and it has been demonstrated [40] that a second phase separation occurs inside the dispersed particles.

On the other hand, the initial miscibility of monomers(s) with additive (Figure 18) has a great influence on the final morphologies. Many experimental results [37-41] show that the phase separation occurs well before gelation ( $t_{\mathrm{gel}}$ or $\left.x_{\mathrm{gel}}\right)$ and vitrification $\left(t_{\mathrm{vit}}, x_{\mathrm{vit}}\right)$. The better the initial miscibility, the higher the conversion at the cloud point, $x_{c p}$ where the phase separation induced by step polymerization occurs at a given isothermal curing temperature, $T_{\mathrm{i}}$ (Fig. 19). Initial miscibility and $T_{\mathrm{i}}$ control the 'chemical quench'. The viscosity at the cloud point, $\eta_{\mathrm{cp}}$ increases obviously with the conversion, $x_{\mathrm{cp}}$. The viscosity $\eta_{\mathrm{cp}}$ can affect the nucleation and growth of the dispersed phase particles and consequently affect the average diameter of the particles $[38,42]$ and, sometimes, also the form of the particles, which is not necessarily spherical.

It is easy to understand that because the reaction progresses during the phase separation process, a thermodynamic equilibrium is never obtained. For this reason it is not easy to control the final morphologies of a sample, it can depend on the thermal gradient inside the sample [43]. This can explain why another approach consisting of dispersing preformed particles in the dry reactive system has been developed. These preformed particles, can be (i) core-shell rubbers (CSR) prepared before by a classical emulsion polymerization [44] or (ii) in situ synthesized preformed particles, for example radical polymerization of an acrylate monomer in the epoxy $[45,46]$.

Cyanate ester monomers form a new type of high performance polymer developed during the 1980s, much later than epoxies. If we take time to describe the rubber- or thermoplastic-modified epoxies approaches, it is because the same approaches have been used to increase the toughness of cyanate ester networks. Cyanate esters can be toughened with engineering thermoplastics [1] (including polysulfone or polyethersulfone, polyimide, polyesters or polyarylates) and elastomers (including butadiene-acrylonitrile co-polymers [1], polysiloxane [47] and CSR [48, 49]. An example of the toughness values with the \% bw of additive is given in Figure 20 .

Cyanate ester networks can also be toughened by the reaction with epoxy. The chain-extension reaction forming oxazolidinone rings increases the molar mass between crosslinks, $\overline{M_{c}}$ and the toughness increases. However, this approach is another concept and is discussed in section 3. 


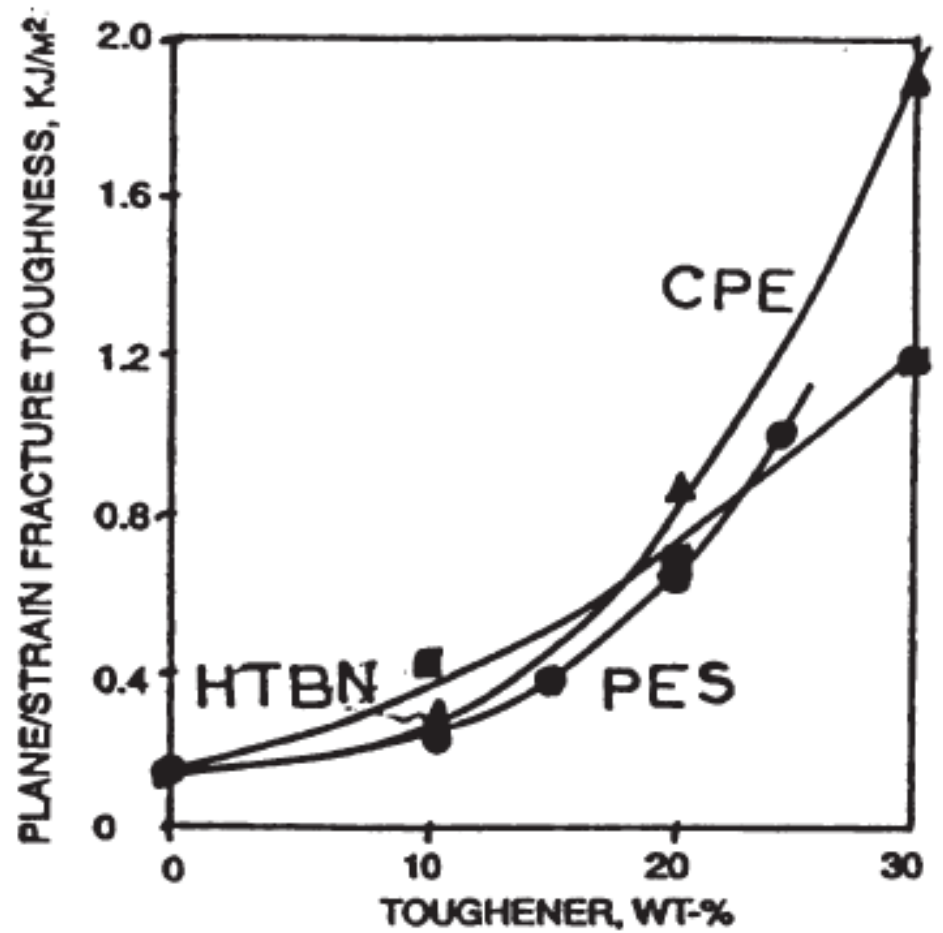

Figure 20. Though inherently tougher than epoxies, cyanate esters respond well to a variety of added tougheners. The toughener efficiencies of HTBN (hydroxy-terminated butadiene-acrylonitrile rubber), CPE (copolyester from Rhone-Poulenc) and PES (polyethersulfone) in Arocy B homopolymer. [1].

From Figure 20 it can be concluded that rubber or thermoplastic modified thermosets work as well with cyanate ester as with epoxy. However, contrary to the case with epoxies, there are few results in the literature giving relations between the initial miscibility of monomer and additive, the curing conditions and the morphologies and properties. For this reason in the next section we summarize some new results obtained in our laboratory [50].

\subsection{Experimental results}

Initial blend. The additives used in this study are rubbers, butadiene-acrylonitrile (AN) random copolymers (Hycar from BF Goodrich) and engineering PES from ICl. The characteristics of the additives are given in Table 4. The influence of the additives on kinetics has been described in section 2 .

In Figure 21 we have plotted the cloud point curve (CPC) obtained with two rubbers, a non-functional one NFBN and a carboxy-terminated one CTBN with the same percentage of AN and two different reactive monomers: a cyanate ester DPEDC and BADGE (DER 332 from Dow). It is evident that the cyanate ester monomer is a better solvent for the rubbers than the epoxy prepolymer. 
Table 4. Structure and characteristics of (a) monomers; (b) elastomers; and (c) engineering thermoplastics used

(a)

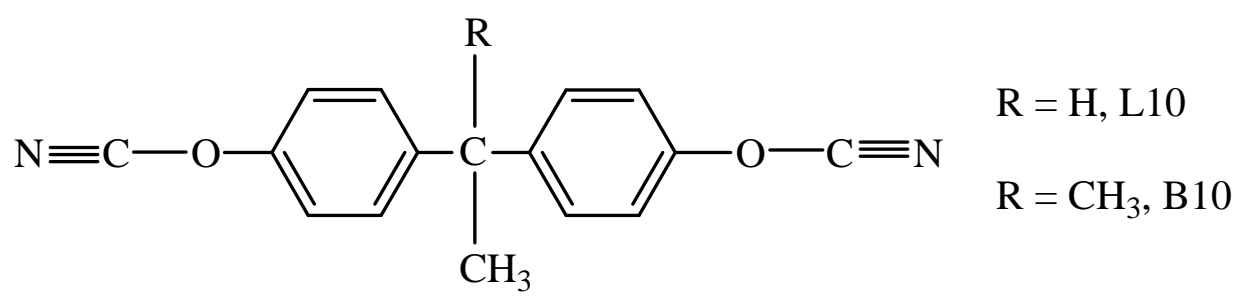

(b)

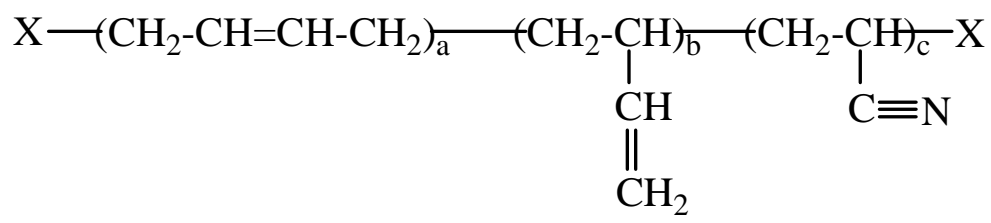

$\mathrm{X}=-\mathrm{NHR}, \mathrm{ATBN}, 10 \%$ and $18 \% \mathrm{AN}$

$\mathrm{X}=-\mathrm{COOH}, \mathrm{CTBN}, 18 \%$ AN

$\mathrm{X}=-\mathrm{CH}_{3}, \mathrm{NFBN}, 18 \% \mathrm{AN}$

(c)

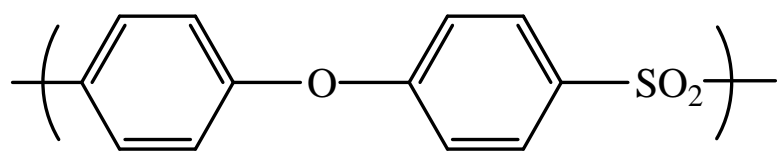

PES

It can also be seen that the NFBN rubber is less miscible than the CTBN rubber. An amino-terminated rubber ATBN 8 with the same amount of AN (18\% bw) is quite miscible with DPEDC or BADGE. Chain ends of reactive liquid oligomers can have a strong effect on their miscibility [51]. By decreasing the percentage AN the miscibility window decreases drastically [52]; for example, ATBN 31 with only $10 \%$ bw AN is quite immiscible at temperatures lower than $100^{\circ} \mathrm{C}$ in DPEDC and BADGE.

PES is miscible with BADGE or DPEDC at room temperature. PES-BADGE blends have a lower critical solubility temperature (LCST) behavior. Owing to cyanate ester reactions at $T>100^{\circ} \mathrm{C}$, the comparison between cyanate ester and BADGE is not possible. We expect a better solvent behavior for cyanate esters, and as the viscosity of cyanate monomers is lower than the viscosity of epoxy, larger amounts of additive can be introduced into cyanate ester formulations. 


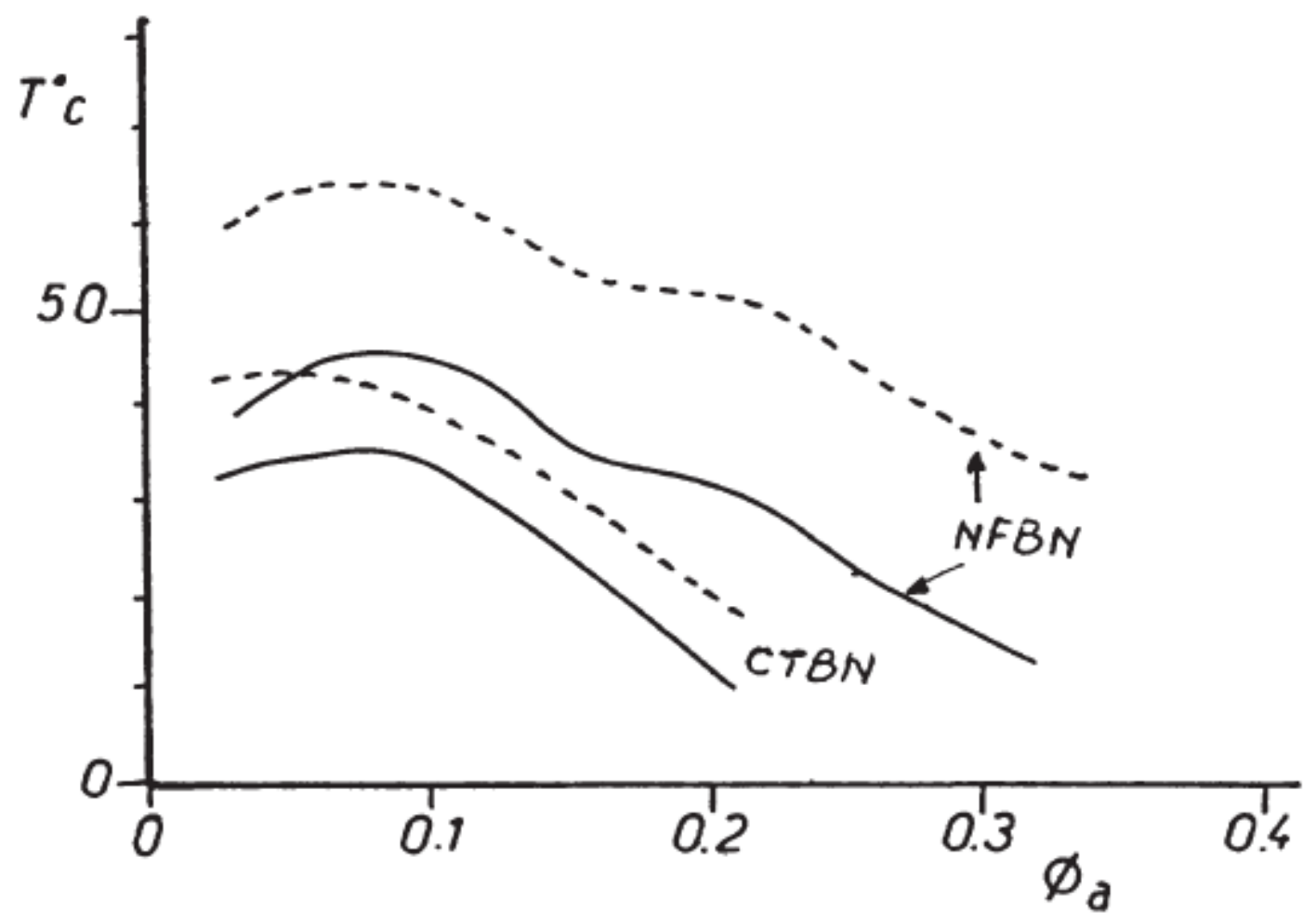

Figure 21. Initial cloud point curve (CPC) for rubber-BADGE (DER332) or rubber-DPEDC (Arocy ${ }^{\circledR}$ L-10) blends: - - -, R = BADGE,,$- \mathrm{R}=$ DPEDC.

Evolution of the reactive blends. The reactivity of additives with cyanate esters is an important question, not only for the phase separation process but also for the adhesion between the two phases at the end of the curing. Reactions of cyanate esters with a nucleophile have been discussed in the first part of this chapter.

(a) Reactivity of additives. Chain ends of ATBN and the excess diamine used to prepare it from CTBN, react with cyanate esters at low temperature, before cyanurate ring formation. Reactions of phenolterminated PES (5003P) are more complex because exchange reactions could occur at high temperature. Nevertheless both additives catalyze the cyclotrimerization reaction and the reaction rate is increased with these additives. With the non-functional additives the cyanate ester reaction rate is constant.

(b) Transitions during polymerization. As we have explained, during the polymerization of an initially miscible mixture of additive and cyanate ester monomer, three transitions defined by reaction time $(t)$ or cyanate conversion $(x)$ could occur:

(i) phase separation experimentally determined by the cloud point, $t_{\mathrm{cp}}$ or $x_{\mathrm{cp}}$

(ii) gelation, $t_{\text {gel }}$ or $x_{\text {gel }}$ defined as the point when the viscosity tends to infinity or when insoluble fractions appear

(iii) vitrification, $t_{\text {vit }}, X_{\text {vit, }}$ when $T_{g(x)}$ of the reactive system reaches the isothermal curing temperature, $T_{\mathrm{i}}$.

These measurements have been described in many publications on modified epoxies [38-40]. 
In the case of cyanate esters, it is possible, for example, to plot the phase diagrams, $x_{\mathrm{cp}}$ versus the mass fraction of additive in the blend, $\Phi_{\mathrm{a}}$, at one isothermal curing temperature. Figures 22 and 23 give the results obtained with DPEDC with different rubbers or thermoplastics; the conclusions are:

(i) with rubbers, $x_{c p}$ increases with increasing initial miscibility:

$x_{\mathrm{cp}}(\mathrm{NFBN})<x_{\mathrm{cp}}(\mathrm{CTBN})<x_{\mathrm{cp}}(\mathrm{ATBN})$

(ii) in the case of ATBN $8, x_{c p}>0.4$, phase separation occurs in a highly viscous medium

(iii) with thermoplastics, the initial phase diagram has not been measured, but Figure 23 shows that the PES with the higher molar mass is less miscible (higher $x_{\mathrm{cp}}$ ) than the one with the lower molar mass.

(c) Phase diagrams. Different experiments with blends with constant $\Phi_{\mathrm{a}}$ have been carried out at different isothermal curing temperatures to plot a phase diagram temperature versus conversion, including phase separation $\left(T_{\mathrm{cp}}, x_{\mathrm{cp}}\right)$, gelation $\left(x_{\mathrm{gel}} \approx 0.60\right)$ and vitrification $\left(T_{\mathrm{vit}}, X_{\mathrm{vit}}\right)$. An example of such a phase diagram is represented in Figure 24 for DPEDC with $15 \%$ bw of a rubber or a thermoplastic additive. From these results different conclusions can be drawn:

(i) cyanate-NFBN is a blend with UCST

(ii) cyanate-PES is a blend with LCST

(iii) at $T_{\mathrm{i}}<200^{\circ} \mathrm{C}$, conversion at the cloud point $x_{\mathrm{cp}}$ is higher with $\mathrm{PES}\left(\overline{M_{n}} \approx 15000-20000\right)$ than with NFBN $\left(\overline{M_{n}} \approx 3600\right)$; at $T_{\mathrm{i}}<200^{\circ} \mathrm{C}$ PES is more miscible with cyanate than NFBN, although the molar mass is higher

(iv) with PES at low isothermal curing temperature, $T_{\mathrm{i}}<90^{\circ} \mathrm{C}, x_{\mathrm{cp}} \approx x_{\mathrm{gel}}$ and no phase separation is observed.

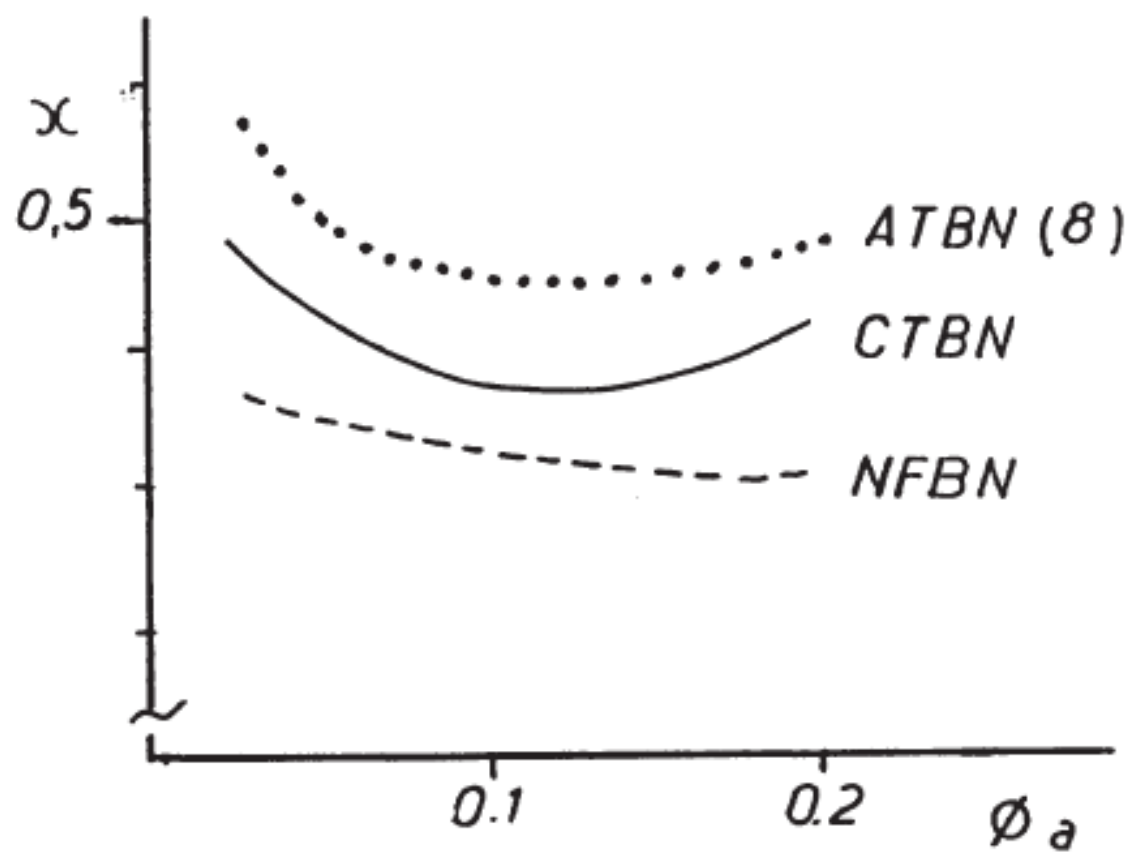

Figure 22. Experimental phase diagram, conversion, $x$, versus the mass fraction of rubber, $\Phi_{a}$ at $T_{\mathrm{i}}=180^{\circ} \mathrm{C}$ (cyanate ester is DPEDC). 


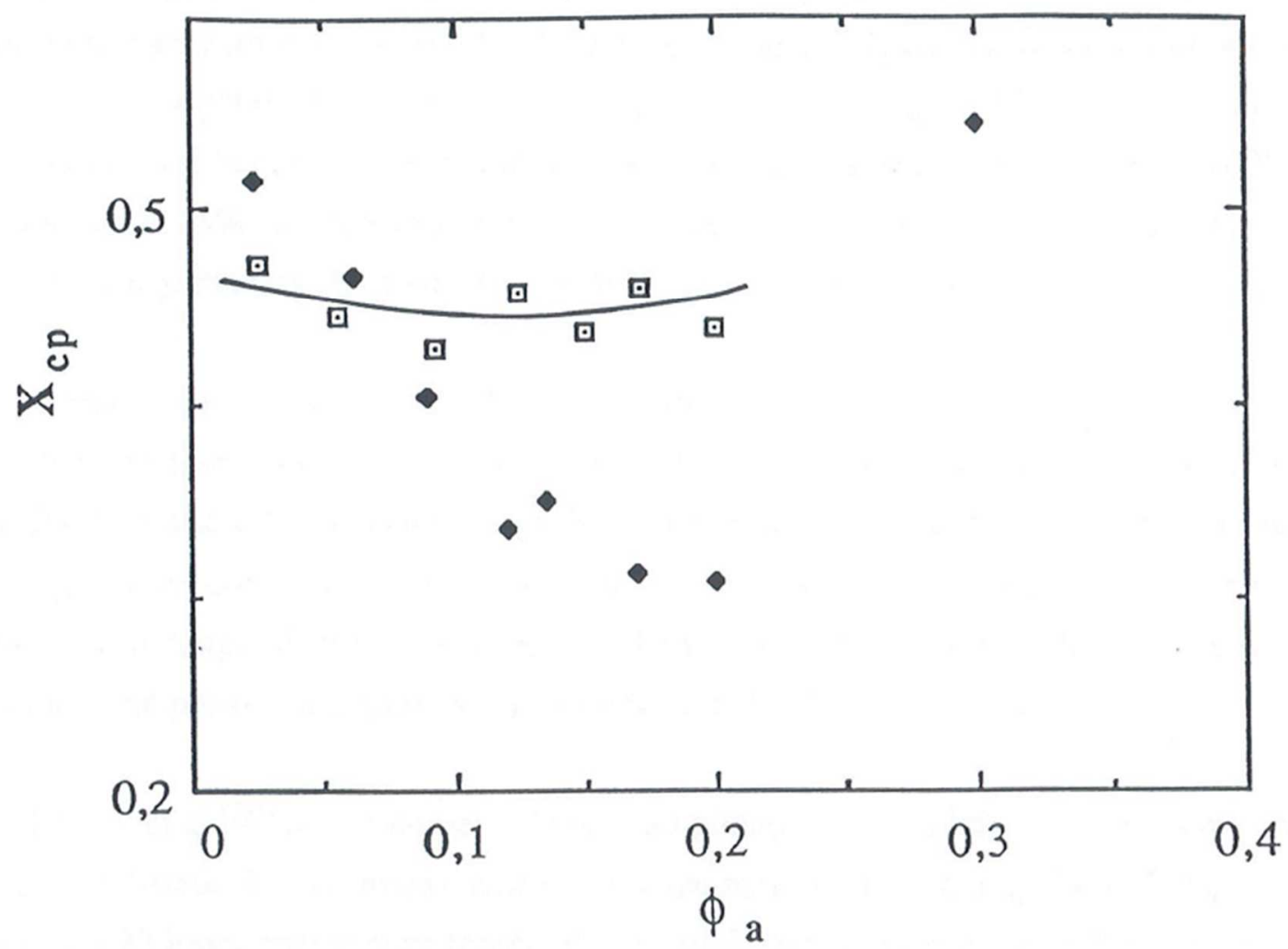

Figure 23. Experimental phase diagram, conversion, $x$, versus the mass fraction of PES. $\Phi_{a}$, at $T_{\mathrm{i}}=180^{\circ} \mathrm{C}$ (cyanate ester is DPEDC); $\square$ : PES 4100P; $\bullet$ : PES 5003P.

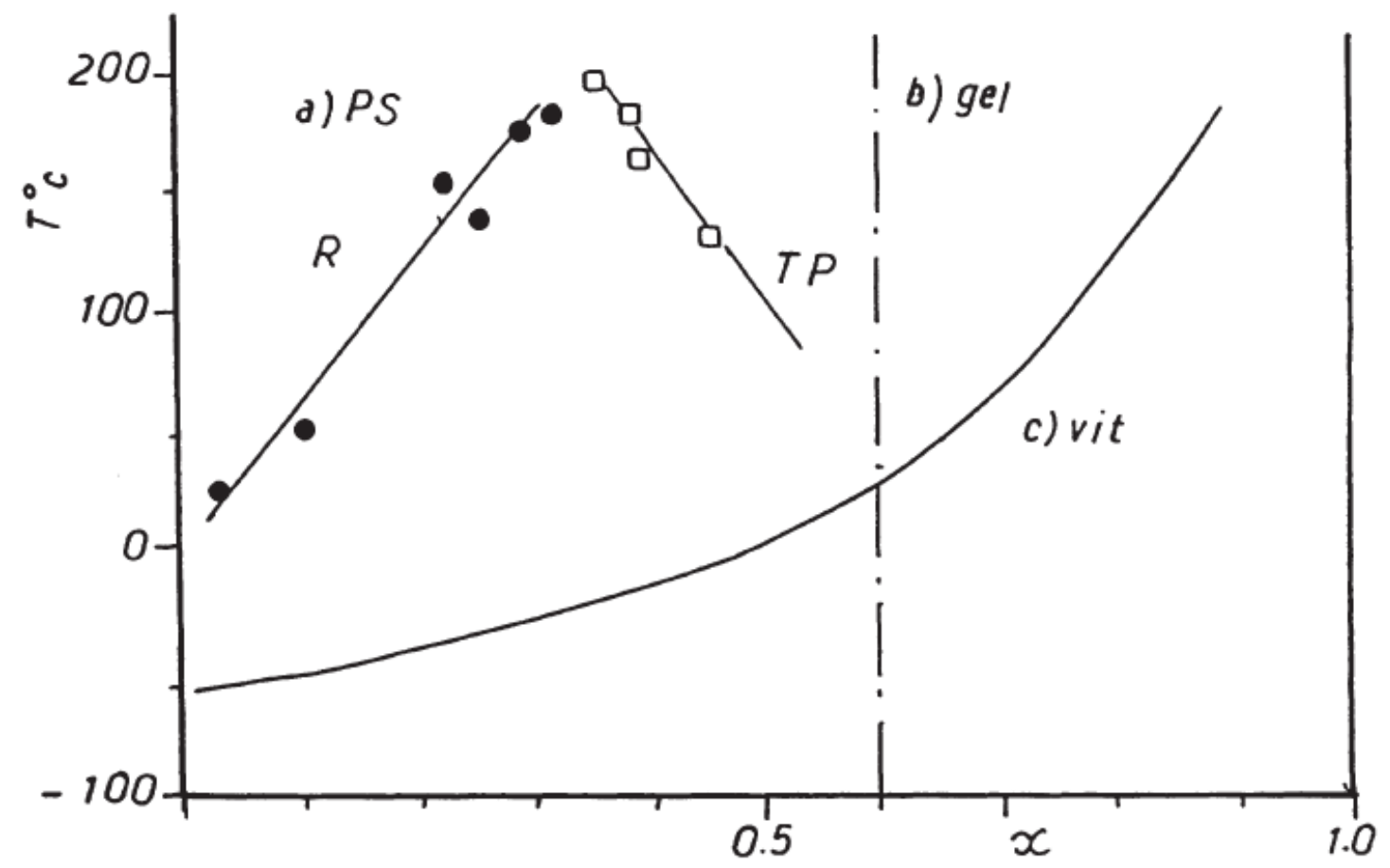

Figure 24. Experimental phase diagram, temperature versus conversion, showing the three transitions: (a) PS: ๑, DPEDC + NFBN; $\square$ DPEDC + PES 5003P; (b) gelation $x \approx 0.6$; (c) vitrification $T_{\mathrm{g}}$ versus $x$. 
(d) Comparison of different systems. This type of phase diagram can be very useful to compare the behavior of different reactive systems. In Figure 25 with the same rubber, 15\% bw of NFBN, we can conclude that DCBA is a better solvent for rubber than DPEDC because $x_{c p}$ (DCBA) $>x_{c p}$ (DPEDC). In Figure 26 we compare for DPEDC the influence of the rubber AN content on the miscibility. ATBN 31 (10\% AN) is quite immiscible with DPEDC at $T<100^{\circ} \mathrm{C}$. Only $5 \%$ bw of ATBN 31 mixed with ATBN 8 drastically shifts the CP curve of a blend DPEDC $+15 \%$ rubber to the lower conversions. By adjusting the percentage $\mathrm{AN}$ it is easy to control the beginning of the phase separation.

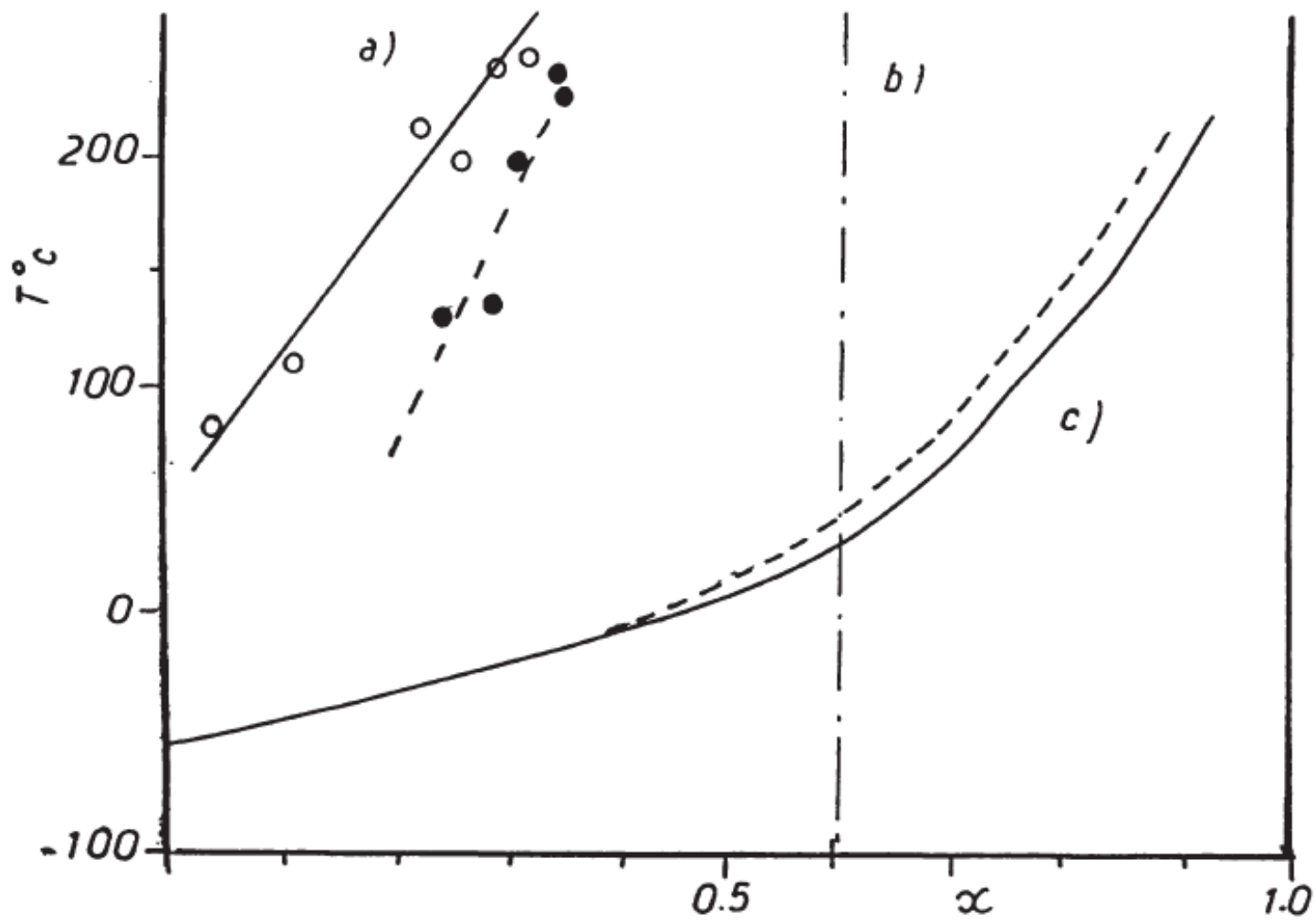

Figure 25. Experimental phase diagram, temperature versus conversion. Comparison between: $\bigcirc$, DPEDC + NFBN; and $\bullet$, DCBA + NFBN. Regions (a)-(c) as in Figure 24.

Morphologies and properties. It is also very useful to control the curing of a blend. Morphologies are mainly controlled by the temperature, $T_{\mathrm{cp}}$ or the viscosity, $\eta_{\mathrm{cp}}$ at which phase separation occurs. Generally when $T_{\mathrm{cp}}$ decreases or $\eta_{\mathrm{cp}}$ (or $x_{\mathrm{cp}}$ ) increases the dispersed particles become smaller. Figure 27 shows a series of micrographs obtained by scanning electron microscopy of the fracture surface of different blends of DPEDC and different additives. They are precured at $T_{\mathrm{i}}=180^{\circ} \mathrm{C}$ to control phase separation and gelation, and postcured at high temperature $\left(260^{\circ} \mathrm{C}\right)$ to control the degree of curing, $x \approx 1$. As we have seen from the phase diagrams, conversion $\left(x_{\mathrm{cp}}\right)$ or viscosity $\left(\eta_{\mathrm{cp}}\right)$ at the cloud point depend on the additive used:

(i) with NFBN, $x_{\mathrm{cp}} \approx 0.30$, the particles are spherical and large, $\bar{D} \approx 7 \mu \mathrm{m}$

(ii) with ATBN, $x_{c p} \approx 0.45$, the particles are smaller $(\bar{D} \approx 1.7 \mu \mathrm{m})$ but they also have a branch-like substructure. In this case, we can expect not only an effect of the viscosity, but certainly also an effect of the reaction between the rubber and the cyanate before network formation

(iii) with PES, $x_{\mathrm{CP}} \approx 0.38$, the particles are also smaller than with NFBN. 


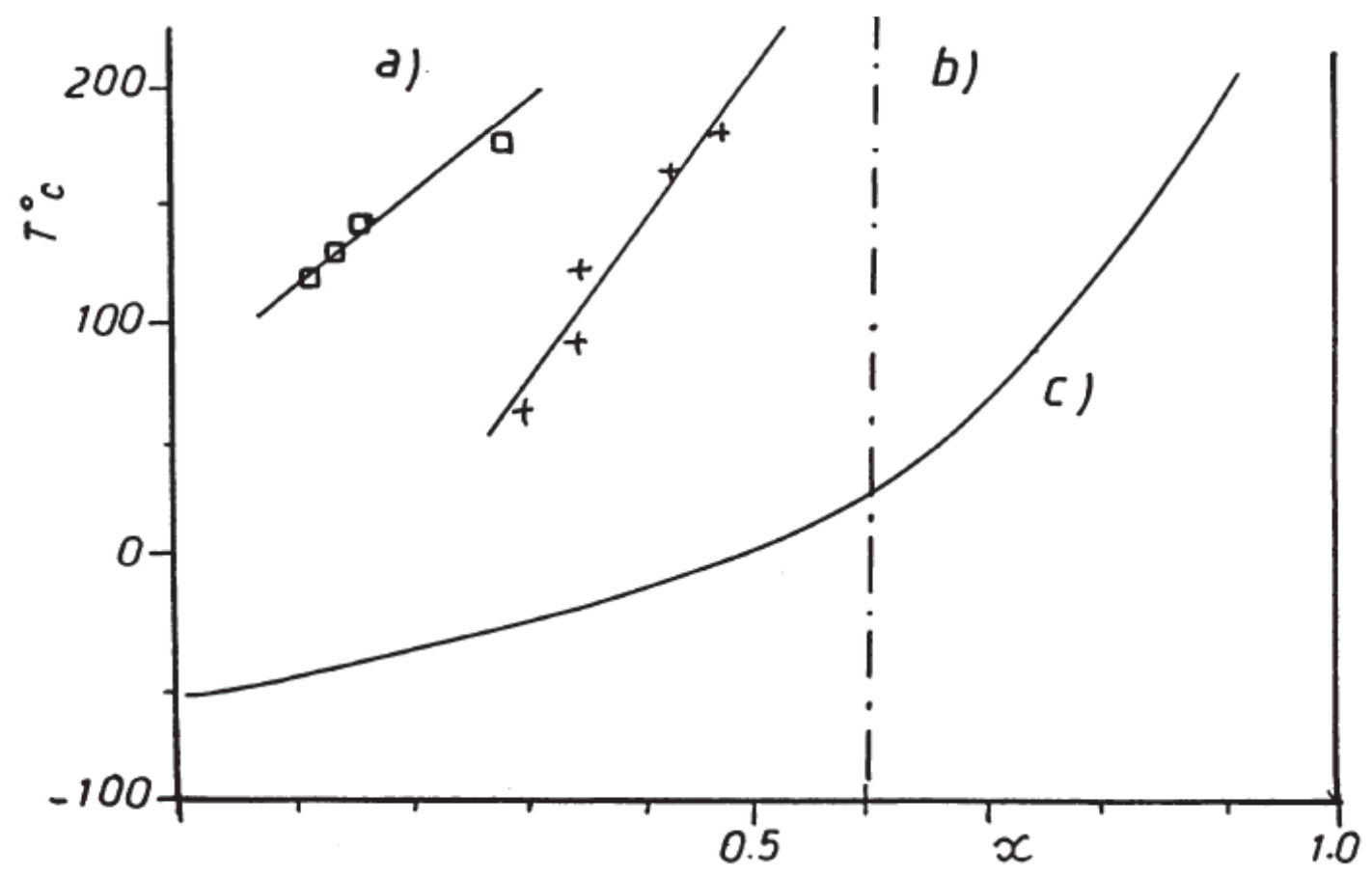

Figure 26. Experimental phase diagram temperature versus conversion. Comparison between: +, DPEDC + ATBN 8; and $\square$ DPEDC + R, R = 95\% ATBN $8+5 \%$ ATBN 31. Regions (a)-(c) as in Figure 24.

We can also have an effect of the viscosity $\eta_{\mathrm{cp}}$ and of the reactive chain ends of the thermoplastic. However, in this case, because $T_{\mathrm{i}}=180^{\circ} \mathrm{C}$ and is lower than the $T_{\mathrm{g}}$ of the thermoplastic, the most important effect is certainly the vitrification of the disperse particles when phase separation occurs. The consequence is that only with thermoplastic as additive, an evolution of the morphology is observed between precuring and post curing processes, $\bar{D}$ decreases from 3 to $1.8 \mu \mathrm{m}$.

Another result from the literature [53] showing how the precuring step is important is given for the catalyzed DPEDC-PES system. The samples precured at $T_{\mathrm{i}}=145$ or $180^{\circ} \mathrm{C}$ have phase separation at $x_{\mathrm{cp}}<x_{\text {gel }}$ (Figure 24) and they ultimately yield a two-phase structure. For a sample procured at $90^{\circ} \mathrm{C}$, phase separation is expected in the same range than gelation $x_{\mathrm{cp}} \approx x_{\mathrm{gel}}$ and the final structure is clear, like a one-phase system.

Adding $20 \%$ bw of PES increases $K_{\mathrm{lc}}$ from 0.3 to $1.7 \mathrm{MPa} \sqrt{m}$ when the blend has a two-phase structure, and it reaches only $0.5 \mathrm{MPa} \sqrt{m}$ when it has a mono-phase. In addition, some experiments have been carried out with PEI (Ultem 1000) and in this case it is always a two-phase structure and $K_{\mathrm{lc}}$ attained 1.7 $\mathrm{MPa} \sqrt{m}[53]$. 
(a)
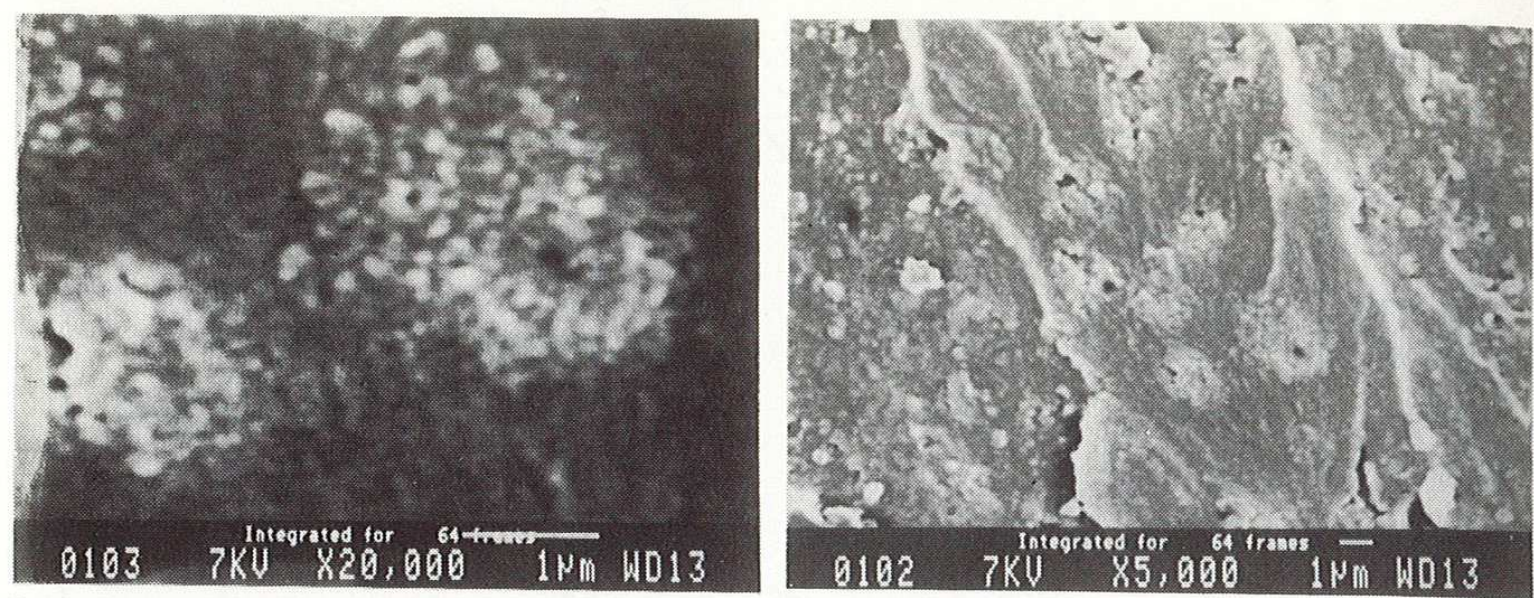

(b)
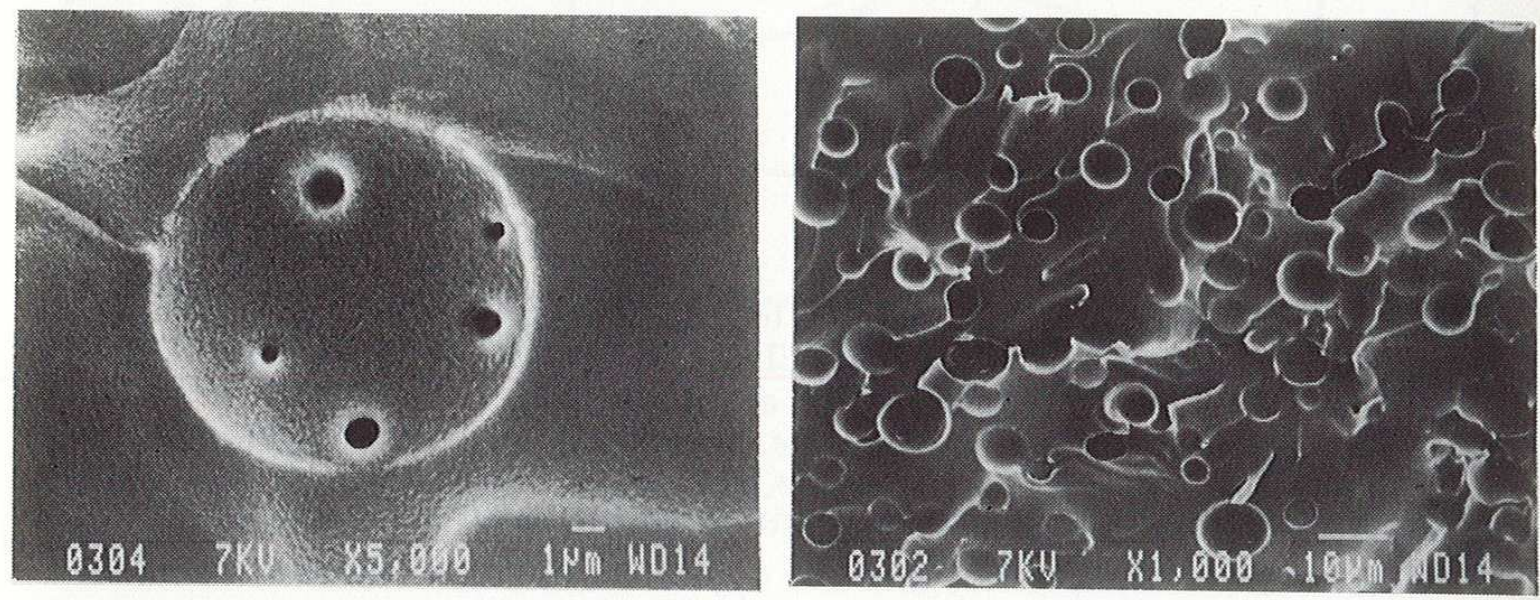

(c)
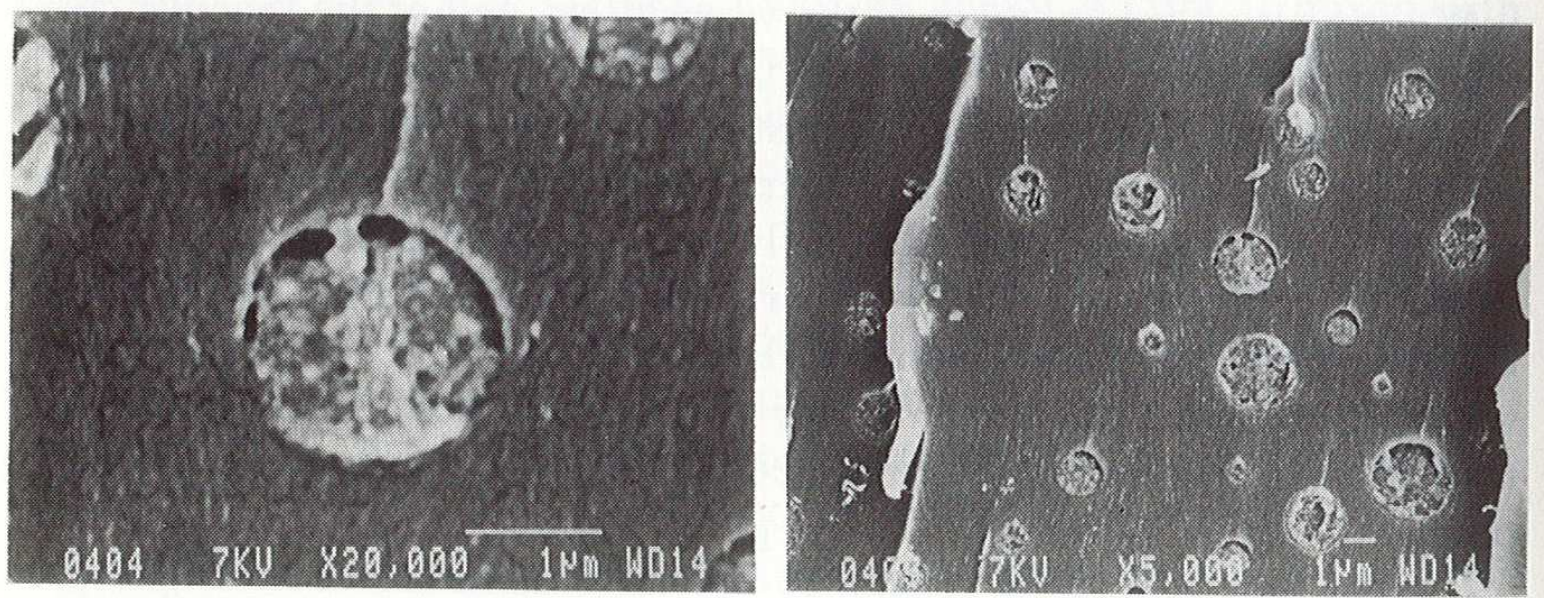

Figure 27. SEM of the cured blends. (a) 15\% ATBN 8 + DPEDC; (b) 15\% NFBN + DPEDC; (c) 15\% PES5003P + DPEDC. 


\section{Conclusions}

This chapter describes the influence of different additives and modifiers on the chemistry of cyanate ester monomers. The polymerization of dicyanates in the presence of phenols is well documented in the literature. However, this is not the case for the roles of the cure atmosphere or water on the kinetics and the mechanism, which are not well understood.

The reaction with epoxy is very complex and water certainly also has a role in the mechanism. Few experiments have been done with diols or diamines as chain extenders. The isourea structure formed with aliphatic or aromatic diamines has a strong catalytic effect on the cyanate ester cyclotrimerization reaction. It means that cyanate chemistry can also be used to crosslink $\alpha, \omega$-functional elastomers.

Cyanate ester networks can be toughened by introducing a rubbery or a thermoplastic dispersed phase. The same concepts used for toughened epoxies work with cyanate esters. When the additive is initially miscible and phase separates during the reaction, the final morphologies are mainly controlled by the temperature and the viscosity at which phase separation occurs. Relationships between morphologies and properties are needed in the case of modified cyanate ester networks.

\section{References}

1. McConnell, V.P. (1992) Advanced Composites, May-June.

2. Fukui, K. and Yamabe, T. (1960) J. Polym. Sci., XLV, 305.

3. Fukui, K. and Yamabe, T. (1967) Bull. Chem. Soc. Japan, 40, 2052.

4. Williams, R.J.J., Vasquez, A. and Pascault, J.P. (1992) Polym. Bull., 28, 219.

5. Bauer, M. and Bauer, J. (1987) Acta Polym., 38, 16.

6. Gupta, A.M. and Macosko, CW. (1991) Makromol. Chem., Macromol. Symp., 45,105.

7. Gupta, A.M. and Macosko, CW. (1993) Macromolecules, 26, 2455.

8. Bauer, M., Bauer, J. and Kühn, G. (1986) Acta Polym., 37, (a) 218; (b) 221; (c) 715.

9. Alla, C (1992) Thesis, Université Pierre et Marie Curie, Paris.

10. Mirco, V., Méchin, F. and Pascault, J.P. (1993) STEPI 3 Proc., Montpellier, June 1-3.

11. Hedayatullah, M. (1967) Bull. Soc. Chim. Fr., 2, 416.

12. Shimp, D.A. and Ising, S.J. (1991) Am. Chem. Soc. Polym. Mat. Sci. Eng. Preprints, 66, 504.

13. Georjon, O., Galy, J. and Pascault, J.P. (1993) J. Appl. Polym. Sci., 49, 1441.

14. Pascault, J.P. and Williams, R.J.J. (1990) J. Polym. Sci. Polym. Phys., 28, 85.

15. Bauer, M. (1980) Thesis, Academy of Science of the GDR, Berlin.

16. Bauer, M., Bauer, J. and Jährig, S. (1991) Makromol. Chem., Macromol. Symp., 45, 97.

17. Cao, Z.Q., Méchin, F. and Pascault, J.P. (1994) Polym. Int., 34, 41.

18. Barthélémy, L., Méchin, F. and Pascault, J.P. unpublished results.

19. Bauer, M., Tänzer, W., Much, H. and Ruhman, R. (1989) Acta Polym. 40 (5), 335. 
20. Bauer, M., Bauer, J., Ruhman, R. and Kuhn, G. (1989) Acta Polym., 40 (6), 397.

21. Shimp, D.A. and Wentworth, J.E. (1992) SAMPE, Los Angeles, 293.

22. Caille, D., Pascault, J.P. and Tighzert, L. (1990) Polym. Bull. 24 (1), 31.

23. Caille, D., Tighzert, L., Pascault, J.P., Grenier-Loustalot, M.F. and Grenier, P. (1993)

Polym. Networks Blends 3 (3), 155.

24. Williams, M.L., Landel, R.F. and Ferry, J.D. (1955) J. Am. Chem. Soc., 77, 3701.

25. Ferry, J.D. (1980) In Viscoelastic Properties of Polymers. Wiley, New York.

26. Jordan, C, Galy, J. and Pascault, J.P. (1992) J. Appl. Polym. Sci., 46, 859.

27. Bauer, J. and Bauer, M. (1990) Acta Polym., 41, 10, 535.

28. Cozzens, R.F., Walter, P. and Snow, A.W. (1987) J. Appl. Polym. Sci. 34, 601.

29. Papathomas, K.I. and Wang, D.W. (1992) J. Appl. Polym. Sci. 44, 1267.

30. Stenzenberger, H.D. (1986) In Structural Adhesives. Development of Resins and Primers, Ch. 4, ed. Kinloch, A.J. Elsevier, London, p. 77.

31. Barton, J.M., Hamerton, I. and Jones, J.R. (1992) Polym. Int., 29, 145.

32. Barton, J.M., Hamerton, I. and Jones, J.R. (1993) Polym. Int., 31, 95.

33. Riew, C.K. and Gillham, J.K. (1984) Rubber-Toughened Thermoset Resins, Adv. in Chem. Ser. 208, Am. Chem. Soc. Washington, DC.

34. Kinloch, A.J. (1986) Rubber-Toughened Thermosetting Polymers in Structural AdhesivesDevelopments in Resins and Polymers, Ch. 5, Ed. Kinloch, A.J. Applied Science, London, p. 127-162.

35. Riew, C.K. (ed.) (1989) Rubber-Toughened Plastics, Adv. in Chem. Ser. 222, Am. Chem. Soc., Washington, DC.

36. Riew, C.K. and Kinloch, A.J. (1993) Toughened Plastics: Science and Engineering, Adv. in Chem. Ser. 233, Am. Chem. Soc., Washington, DC.

37. Williams, R.J.J., Borrajo, J., Adabbo, H.E. and Rojas, AJ. (1984) In Rubber-Toughened Thermoset Resins, Adv. in Chem. Ser. 208, Am Chem. Soc., Washington, DC, pp. 195-213.

38. Montarnal, S., Pascault, J.P. and Sautereau, H. (1989) In Rubber-Toughened Plastics, Adv. in Chem. Ser., 222, Am. Chem. Soc., Washington, DC., pp. 193-224.

39. Verchère, D., Sautereau, H., Pascault, J.P., Moschiar, S.M., Riccardi, C.C. and Williams, R.J.J. (1993) In Toughened Plastics: Science and Engineering, Adv. in Chem. Ser., 233, Am. Chem. Soc., Washington, DC., pp. 335-363.

40. Chen, D., Pascault, J.P., Sautereau, H. and Vigier, G., (1993) Polym.Int., in press.

4!. Manzione, L.T., Gillham, J.K. and McPherson, C.C. (1981) J. Appl. Polym. Sci., 26, 889.

42. Ruseckaite, RA., Hu, L.J., Riccardi, C.C. and Williams, RJ.J. (1993) Polym. Int., 30, 287.

43. Pu Fang, D., Frontini, P.M., Riccardi, C.C. and Williams, R.J.J. (1993) Polym. Eng. Sci., in press. 
44. Sue, H.J., Garcia-Meitin, E.I., Pickelman, D.M. and Yang, P.C. (1993) In Toughened Plastics; Science and Engineering, Adv. in Chem. Ser., 233, Am. Chem. Soc., Washington DC, pp. 259-292.

45. Hoffman, D.W., Kobb, G.C., Arends, C.B. and Stevens, M.G.(1985) Polym. Preprints, 26, 232.

46. Pocius, A.V., Schultz, W.J., Thompson, W.L. and Adam, R.A. (1993) J. Adhes. 41, 189.

47. Arnold, e.. McKenzie, P., Malhotra, V., Pearson, D., Chow. N., Hearn. M. and Robinson, G. (1992) 37th Int. SAMPE Symp. 37,128-136.

48. Yang, P.C., Pickelman, D.M. and Woo. E.P. (1990) 35th Int. SAMPE Symp. 35,408.

49. Yang, P.C., Woo, E.P., Laman. S.A., Jakylowski, J.J., Pickelman, D.M. and Sue, H.J. (1991) 36th Int. SAMPE Symp. 36, 437.

50. Cao, Z.Q., Doctoral Thesis, INSA de Lyon (France), in preparation.

51. Chen, D., Pascault, J.P., Bertsch, RJ., Drake, RS. and Siebert, A.R. (1994) J. Appl. Polym. Sci., 51, 1959.

52. Verchère, D., Sautereau, H., Pascault, J.P., Riccardi, C.C., Moschiar, S.M.M. and Williams, R.J.J. (1989) Polymer, 30,107.

53. Pellan, L. and Bloch, B. (1992) 8th Journées Nationales sur les Composites, p. 161-172. 